February 2007

\title{
A Generalization of the Calendar Time Portfolio Approach and the Performance of Private
}


The Author(s):

Daniel Hoechle

Center of Business and Economics (WWZ), University of Basel

Holbeinstrasse 12

CH-4051 Basel

daniel.hoechle@unibas.ch

\section{Prof. Dr. Heinz Zimmermann}

Center of Business and Economics (WWZ), University of Basel

Holbeinstrasse 12

CH-4051 Basel

heinz.zimmermann@unibas.ch

A publication oft the Center of Business and Economics (WWZ), University of Basel.

(C) WWZ Forum 2007 and the author(s). Reproduction for other purposes than the personal use needs the permission of the author(s).

\section{Contact:}

WWZ Forum | Petersgraben 51 | CH-4003 Basel | forum-wwz@unibas.ch |www.wwz.unibas.ch 


\title{
A Generalization of the Calendar Time Portfolio Approach and the Performance of Private Investors*
}

\author{
Daniel Hoechle ${ }^{\dagger}$ \\ University of Basel
}

\author{
Heinz Zimmermann \\ University of Basel
}

This version: February 15, 2007

\begin{abstract}
We present a regression-based generalization of the calendar time portfolio approach which allows for the inclusion of continuous and multivariate investor or firm characteristics in the analysis. Our method is simple to apply and it ensures that the statistical results are heteroscedasticity consistent and robust to very general forms of cross-sectional and temporal dependence. Furthermore, our regression-based technique also remedies several well-known weaknesses of the traditional calendar time portfolio approach. By considering a new, unique dataset on more than 40,000 European private investors, we illustrate empirically that erroneously ignoring cross-sectional dependence inherent in microeconometric panel data can lead to severely biased statistical results. Moreover we use our method to validate some of the most popular hypotheses on the performance of private investors.
\end{abstract}

Keywords: Performance measurement, Robust statistical inference, Cross-sectional dependence

JEL classification: $\mathrm{C} 21, \mathrm{G} 14, \mathrm{D} 1$

* We would like to thank an anonymous wholesale bank for providing the data on individual investors' trades, monthly position statements, and demographics. Special thanks go to Alexander Girardi for his great help in obtaining (and understanding) this complex and comprehensive dataset. We thank Matthias Bürgin, John Driscoll, Matthias Grüninger, Christian Kleiber, David Rey, Markus Schmid, and Clemens Sialm for useful insights and helpful comments. Daniel Hoechle would like to acknowledge the financial support from the Stiftung Basler Bankenplatz.

$\dagger$ Department of Finance, University of Basel, Holbeinstrasse 12, CH-4051 Basel, Switzerland, Tel.: +41-61267-3243, e-mail: daniel.hoechle@unibas.ch

$\ddagger$ Department of Finance, University of Basel, Holbeinstrasse 12, CH-4051 Basel, Switzerland, Tel.: +41-61267-3316, e-mail: heinz.zimmermann@unibas.ch 


\section{Introduction}

Due to social norms, corporate timing, and all kinds of psychological behavior patterns, microeconometric data is likely to be cross-sectionally (or "spatially") dependent. This potential dependence constitutes a challenge for the analysis of panel data on the firm or private investor level, as it is well known that erroneously ignoring spatial correlation can lead to severely biased statistical results. Empirical scientists have therefore devoted great efforts in developing methodologies which ensure that statistical inference is valid even in the presence of crosssectional dependence. One of the most popular techniques that has emanated from this research is the calendar time portfolio approach (or the Jensen alpha approach) whose origin goes back to the work of Jaffe (1974) and Mandelker (1974). The calendar time portfolio approach (subsequently abbreviated as the CalTime approach) as it is employed in recent studies constitutes a two-step procedure. Thereby, the first step involves computing an average return for the crosssection of investors or firms, and the second step then measures the risk-adjusted performance by estimating a multifactor (e.g. the Fama-French three factor) time-series regression model.

In this paper, we present a regression-based generalization of the CalTime approach. Our methodology relies on estimating, either on the investor or firm level, a linear regression model with Driscoll and Kraay (1998) standard errors. We show both theoretically and empirically, that this "GCT-regression model" is capable to replicate the results of the traditional calendar time portfolio approach in a single step rather than in two. Since Driscoll-Kraay standard errors are spatial correlation consistent, our methodology further confirms the findings of Lyon, Barber, and Tsai (1999, p. 193) who report that the calendar time portfolio approach "eliminates the problem of cross-sectional dependence among sample firms because the returns on sample firms are aggregated into a single portfolio".

Although we focus in this study on the performance of private investors, our insights can be applied to any research that relies on microeconometric panel data. This is important to note since the CalTime approach is utilized in many different areas of empirical finance. As such, this methodology is not only popular in studies on the performance of private investors (e.g. 
Barber and Odean, 2000, 2001, 2002; Seasholes and Zhu, 2005, 2006; Ivkovic, Sialm, and Weisbenner, 2006; Kumar and Lee, 2006), but also in research on the long-run performance of stocks (e.g. Brav and Gompers, 1997; Fama, 1998; Mitchell and Stafford, 2000; Hertzel, Lemmon, Linck, and Rees, 2002; Gompers and Lerner, 2003) and in studies on insider trading (e.g. Jaffe, 1974; Eckbo and Smith, 1998; Jeng, Metrick, and Zeckhauser, 2003).

While Fama (1998) and Mitchell and Stafford (2000) strongly advocate the CalTime approach, this technique is by no means accepted without criticism. Most prominently, Loughran and Ritter (2000) complain that analyzing an unbalanced panel with this approach underweights observations from periods with large cross-sections and overweights observations from periods with small cross-sections. In private investor research on which we focus on in this study, this feature of the CalTime approach is problematic because it underweights the investors' decision of whether or not to hold stocks in a given month. Correspondingly, Loughran and Ritter (2000, p. 363) argue that "tests that weight firms equally should have more power than tests that weight each time period equally". By relying on the estimation of a linear regression model, our generalization of the CalTime methodology naturally resolves the critique of Loughran and Ritter (2000) as it is straightforward to estimate our "GCT-regression model" with OLS.

Even though the CalTime approach allows for valid statistical inference when cross-sectional dependence is present, its applicability is limited to the analysis of a single, binary investor characteristic. Although it is sometimes possible to objectively segregate investors into clearcut groups such as men and women, some research questions necessitate a subjective specification of the characteristics that make an investor belong to a certain group or not. Moreover, with the CalTime approach it is quite intricate to perform robustness checks. In particular, the CalTime methodology makes it impossible to include investor specific explanatory variables (e.g. the portfolio size or the age of an investor) into the time-series regression of the second step. In contrast, our regression-based generalization of the CalTime approach is not limited to an analysis of single and binary investor characteristics. On the contrary, it is straightforward to include continuous and multivariate investor characteristics in the analysis. Therefore, our GCT-regression model makes it both simple to perform robustness checks and straightforward 
to control for alternative investor characteristics and concurring hypothesis, respectively.

Because the traditional CalTime approach is incapable to deal with continuous and multivariate investor characteristics, researchers have recently started to investigate the performance of private investors with cross-sectional regressions on the investor level. Like the traditional CalTime approach, this alternative technique (which we refer to as the CrossReg methodology) constitutes a two-step procedure. However, compared to the calendar time portfolio approach, the ordering of the two steps that are inherent in the analysis is reversed. Thus, the first step of the CrossReg procedure involves estimating a Fama and French (1993) type mutifactor model for each single investor, and the second step then aggregates the investors by regressing the Fama-French alphas from the first step on a set of investor specific explanatory variables.

In early applications, the CrossReg methodology has been used in research on the performance of mutual funds (see e.g. Dahlquist, Engström, and Söderlind, 2000). More recently, however, this technique has started to become popular in research on the behavior and performance of private investors. As such, Ivkovic and Weisbenner (2005) and Korniotis and Kumar (2006) implement the CrossReg methodology as it is outlined above. Moreover, Feng and Seasholes (2004b), Goetzmann, Massa, and Simonov (2004), Ivkovic, Sialm, and Weisbenner (2006), and Massa and Simonov (2006) also estimate cross-sectional (panel) regressions which in some cases may be shown to belong to the CrossReg class.

In this paper, we show that the coefficient estimates from the CrossReg approach coincide with those of our "GCT-regression model". However, this is not the case for the standard errors because it is impossible to estimate spatial correlation consistent standard errors for a regression model of a single cross-section (Driscoll and Kraay, 1998). As a result, the secondstep regression of the CrossReg approach will always be based on the (implicit) assumption that the portfolio returns of the individual investors are cross-sectionally uncorrelated.

Although this presumption might look innocent for a random sample of private investors, it is not. As such, cross-sectional dependence in the portfolio returns of private investors is likely to arise due to at least two reasons. Besides the fact that social norms, herd behavior, and neighborhood effects can lead to contemporaneously correlated actions of the investors (Feng 
and Seasholes, 2004a; Kumar and Lee, 2006; Dorn, Huberman, and Sengmueller, 2005), there is also a technical reason of why stock returns of private investors are likely to be spatially dependent. Specifically, Seasholes and Zhu (2005, p. 4) argue that "over a single time period the return to any household's portfolio is simply a linear combination of the underlying assets' returns. The number of independent household returns is thus limited by the number of assets and not the number of households." Because of the potential consequences of erroneously ignoring cross-sectional dependence in the data (Driscoll and Kraay, 1998), the CrossReg approach is therefore at risk of producing severely biased statistical results. Indeed, by analyzing a unique dataset with account-level data on more than 40,000 private investors we find that (erroneously) ignoring cross-sectional dependence inherent in the data can result in t-values that are three and more times higher than the spatial dependence consistent t-values of our GCT-regression model.

The remainder of this paper is structured as follows. Section 2 formalizes our methodology. In Section 3 we describe our investor sample. Section 4 empirically illustrates our generalization of the calendar time portfolio approach. Furthermore, it validates some of the most popular hypotheses on the performance of private investors. Section 5 concludes.

\section{Methodology}

In the first part of this section, we revisit the calendar time portfolio methodology (or the Jensen-alpha methodology) which has originally been introduced by Jaffe (1974) and Mandelker (1974). We then present a panel regression based approach which yields as a special case identical coefficient estimates and standard errors as the CalTime approach. Finally, we show that our "GCT-regression model" can also be used to replicate the coefficient estimates of the CrossReg approach. However, because the standard errors and t-stats of the CrossReg methodology can not be adjusted such that they are robust to cross-sectional dependence in the data, the standard errors and $t$-stats of the CrossReg approach are different from those of the GCT-regression model. 


\subsection{The calendar time portfolio approach}

In the first step of the CalTime methodology one constructs for each investor group a timeseries of the group's mean excess return. This is achieved by averaging the month $t$ excess returns $y_{h t}$ of all $N_{j t}$ investors $h$ who belong to group $j$ as ${ }^{1}$

$$
y_{j t}=\frac{1}{N_{j t}} \sum_{h=1}^{N} z_{h t}^{(j)} y_{h t}
$$

where $z_{h t}^{(j)}$ is a dummy variable which is equal to one if investor $h$ belongs to investor group $j$ and zero otherwise. The second step of the most recent variants of the CalTime methodology then measures the performance of the investor groups by aid of a linear $k$-factor regression model with $y_{j t}$ from (1) as the dependent variable:

$$
y_{j t}=\beta_{j 0}+\beta_{j 1} x_{1 t}+\ldots+\beta_{j k} x_{k t}+\epsilon_{j t} .
$$

In most applications, equation (2) is specified as a Jensen (1968), Fama and French (1993), or Carhart (1997) type regression. Therefore, the coefficient estimate for the intercept term $\left(\hat{\beta}_{j 0}\right)$ is typically of prime interest for judging whether or not investor group $j$ performs well.

The use of the CalTime methodology is by no means limited to an analysis of the investment performance of single investor groups. It is straightforward to compare the performance of two investor groups. For instance, if a researcher wants to investigate whether or not women $(j=$ $w)$ have superior investment skills compared to men $(j=m)$, she may do so by constructing a zero investment portfolio which is long in the women's portfolio and short in the portfolio of the men. Thus, in this case the dependent variable of the second step regression is given by $\Delta y_{t}=y_{w t}-y_{m t}$. If women outperform (underperform) men, then the coefficient estimate for

\footnotetext{
${ }^{1}$ The term "investor group" should not be taken too literally. For instance, instead of forming investor group portfolios one could also construct portfolios of firms or portfolios that are based on certain asset holdings (see e.g. Seasholes and Zhu, 2006). Furthermore, note that the CalTime methodology is by no means restricted to a first step aggregation of individual excess returns. In fact, any variable $y_{h t}$ which varies over both $t$ and $h$, respectively, may be aggregated in the first step of the procedure.
} 
$\beta_{\Delta 0}$ from the $k$-factor regression model

$$
\Delta y_{t}=\beta_{\Delta 0}+\beta_{\Delta 1} x_{1 t}+\ldots+\beta_{\Delta k} x_{k t}+\epsilon_{\Delta t} .
$$

should be positive (negative) and significantly different from zero.

\subsection{A regression-based replication of the CalTime approach}

The two-step version of the CalTime methodology discussed so far is widely applied in empirical finance. However, it is possible to completely replicate the results of the calendar time portfolio approach by aid of a pooled linear regression model with Driscoll and Kraay (1998) standard errors as follows: ${ }^{2}$

$$
\begin{aligned}
y_{h t}= & d_{0,0}+d_{0,1} x_{1 t}+d_{0,2} x_{2 t}+\ldots+d_{0, k} x_{k t} \\
& +d_{1,0} z_{h t}^{(w)}+d_{1,1} z_{h t}^{(w)} x_{1 t}+\ldots+d_{1, k} z_{h t}^{(w)} x_{k t}+v_{h t}
\end{aligned}
$$

As in expression (1), $y_{h t}$ refers to the month $t$ excess return of investor $h$. Regression (4) contains three types of explanatory variables. First, the regression includes the same $k$ market variables $x_{s t}(s=1, \ldots, k)$ as does the second step regression (3) of the CalTime approach. The market level variables vary over time but not between the investors. Second, the dummy variable $z_{h t}^{(w)}$ is investor specific (and possibly time-varying). It takes on a value of one if an investor belongs to investor group $j=w$ which constitutes the long position in $\Delta y_{t}=y_{w t}-y_{m t}$ and zero for investors from group $j=m$. In our previous example, where the researcher wants to investigate whether or not women outperform men, $z_{h t}^{(w)}$ is 1 for women and zero for men. Third and finally, regression (4) contains a full set of interaction terms between $z_{h t}^{(w)}$ and the $k$ market level variables $x_{s t}(s=1, \ldots, k)$.

To replicate the results of the CalTime approach when variable $z_{h t}^{(w)}$ is time-varying or when

\footnotetext{
${ }^{2}$ Note that the Driscoll and Kraay (1998) covariance matrix estimator does only work for balanced panels. However, Hoechle (2006) adjusts the Driscoll-Kraay estimator for use with unbalanced panels and it is this adjusted estimator which we use in the empirical analysis of Section 4.
} 
the investor panel is unbalanced, regression (4) has to be estimated by weighted least squares (WLS). As we illustrate empirically in Section 4.2, choosing observation weights equal to $w_{h t}^{(j)}=N_{j t}^{-1}$ (with $j=m, w$ ) completely reproduces the results of the traditional two-step version of the CalTime methodology. For mathematical tractability, however, we restrict our formal treatment of the regression based replication of the CalTime approach to the case of a balanced panel with $N$ investors, $T$ time periods, and two investor groups $j=m, w$ which are constant over time. Under these assumptions, ordinary least squares (OLS) regression of (4) suffices to reproduce the results of the CalTime approach. This is summarized in the following proposition:

\section{Proposition 1 - coefficient estimates}

In a balanced panel with $N$ investors, $T$ time periods, and two investor groups $j=m, w$ which are constant over time it holds true that:

1. OLS coefficient estimates for $\beta_{\Delta s}(s=0,1, \ldots, k)$ in regression (3) are identical to the OLS coefficient estimates for $d_{1, s}$ in regression (4), i.e. $\hat{\beta}_{\Delta s} \equiv \hat{d}_{1, s} \forall s=0,1, \ldots, k$.

2. For investor group $j=m$, OLS coefficient estimates for $\beta_{m s}(s=0,1, \ldots, k)$ in regression (2) are identical to the OLS coefficient estimates for $d_{0, s}$ in regression (4), i.e. $\hat{\beta}_{m s} \equiv \hat{d}_{0, s}$ $\forall s=0,1, \ldots, k$.

Proof: See appendix.

In order to replicate for investor group $j=w$ the coefficient estimates of the CalTime approach in (2), we apply the results of Proposition 1 and use $y_{w t}=y_{m t}+\Delta y_{t}$ to obtain the following corollary:

Corollary $1 \hat{\beta}_{w s}=\hat{\beta}_{m s}+\hat{\beta}_{\Delta s}=\hat{d}_{0, s}+\hat{d}_{1, s}(s=0,1, \ldots, k)$.

However, the regression model in (4) not only replicates the coefficient estimates of the CalTime methodology. As we show in the appendix, this regression model may also be used to reproduce the standard error estimates of the CalTime approach. This brings us to the following proposition: 
Proposition 2 - standard errors

For a given lag length choice $H$ and under the assumptions of Proposition 1, it holds true that:

1. Newey and West (1987) standard errors (without degree-of-freedom correction) for the coefficient estimates of regression (3) are identical with Driscoll and Kraay (1998) standard errors for the coefficient estimates of $d_{1, s}(s=0,1, \ldots, k)$ in regression (4).

2. For investor group $j=m$, Newey and West (1987) standard errors (without degreeof-freedom correction) for the coefficient estimates of regression (2) are identical with Driscoll and Kraay (1998) standard errors for the coefficient estimates of $d_{0, s}(s=$ $0,1, \ldots, k)$ in regression (4).

Proof: See appendix.

Proposition 2 makes intuitive sense because according to Driscoll and Kraay (1998, p. 552) their "covariance matrix estimator is precisely the standard Newey and West (1987) heteroskedasticity and serial correlation consistent covariance matrix estimator, applied to the sequence of cross-sectional averages" of the moment conditions. Thus, one might argue that the calendar time portfolio approach basically replicates Driscoll-Kraay standard errors by aid of a two-step procedure. Since Driscoll and Kraay (1998) prove that their nonparametric covariance matrix estimator is robust to very general forms of cross-sectional and temporal dependence, Proposition 2 therefore confirms the finding of Lyon, Barber, and Tsai $(1999$, p. 193) that the CalTime approach "eliminates the problem of cross-sectional dependence".

\subsection{Generalizing the calendar time portfolio approach}

The original two-step version of the calendar time portfolio approach discussed in Section 2.1 is limited to the analysis of clearly specified investor groups. Furthermore, since it is impossible to include investor specific explanatory variables (such as the portfolio size) into the second step regression (3) of the CalTime approach, the analysis turns out to be rather one-dimensional 
and it is quite intricate to perform robustness checks. Finally, Loughran and Ritter (2000, p. 362) complain that by equally weighting each time period instead of each observation, the traditional calendar time portfolio methodology has "low power to identify abnormal returns for events that occur as a result of behavioral timing". 3

In contrast to the traditional two-step version of the calendar time portfolio methodology, the regression based replication of the CalTime approach in (4) does not suffer from these shortcomings. In particular, estimating regression (4) with OLS naturally overcomes the critique of Loughran and Ritter (2000). Furthermore, it is straightforward to generalize regression (4). The first possibility is to replace the dichotomous variable $z_{h t}^{(w)}$ by a continuous variable $z_{h t}$ which makes it unnecessary to segregate investors into clear cut groups. Moreover, one can augment regression (4) by including additional investor specific variables. This constitutes a possibility to add control variables to the regression and to perform robustness checks. However, in order to maintain the fundamental structure of regression model (4), it is important to also include all interaction terms between the investor characteristics $\left(z_{q h t}\right)$ and the market variables $\left(x_{s t}\right)$. To see this, we rewrite regression (4) by aid of the Kronecker product as ${ }^{4}$

$$
\begin{aligned}
y_{h t} & =d_{0,0}+d_{0,1} x_{1 t}+\ldots+d_{0, k} x_{k t}+d_{1,0} z_{h t}+d_{1,1} z_{h t} x_{1 t}+\ldots+d_{1, k} z_{h t} x_{k t}+v_{h t} \\
& =\left(\left[1 z_{h t}\right] \otimes\left[1 x_{1 t} \ldots x_{k t}\right]\right) \mathbf{d}+v_{h t} \\
& =\left(\mathbf{z}_{h t} \otimes \mathbf{x}_{t}\right) \mathbf{d}+v_{h t}
\end{aligned}
$$

where the $2(k+1) \times 1$ dimensional column vector $\mathbf{d}$ contains the regression coefficients, $\mathbf{x}_{t}$ comprises the market level variables, and $\mathbf{z}_{h t}$ embodies the investor characteristic. From (5) it is obvious that adding an investor specific variable $z_{\mu h t}$ changes the fundamental structure of the regression model unless $z_{\mu h t}$ is part of vector $\mathbf{z}_{h t}$. However, augmenting $\mathbf{z}_{h t}$ with $z_{\mu h t}$ implies that in addition to $z_{\mu h t}$ all interaction terms between $z_{\mu h t}$ and the $k$ market variables $x_{s t}$ $(s=1, \ldots, k)$ are included in the regression. As a generalization of the CalTime approach, we

\footnotetext{
${ }^{3}$ To circumvent this problem, Fama (1998) and Lyon, Barber, and Tsai (1999) suggest to estimate the timeseries regression in (3) by aid of weighted least squares (WLS) regression with observation weights set equal to their statistical precision.

${ }^{4}$ In (5) we exchange dummy variable $z_{h t}^{(w)}$ with variable $z_{h t}$ which is allowed to be continuous.
} 
therefore suggest to estimate by OLS the following linear regression model with Driscoll and Kraay (1998) standard errors: ${ }^{5}$

$$
\begin{aligned}
y_{h t}= & \left(\left[1 z_{1 h t} \ldots z_{m h t}\right] \otimes\left[1 x_{1 t} \ldots x_{k t}\right]\right) \mathbf{d}+v_{h t} \\
= & d_{0,0}+d_{0,1} x_{1 t}+\ldots+d_{0, k} x_{k t} \\
& +d_{1,0} z_{1 h t}+d_{1,1} z_{1 h t} x_{1 t}+\ldots+d_{1, k} z_{1 h t} x_{k t} \\
& +\ldots \\
& +d_{m, 0} z_{m h t}+d_{m, 1} z_{m h t} x_{1 t}+\ldots+d_{m, k} z_{m h t} x_{k t}+v_{h t}
\end{aligned}
$$

While the $k$ market variables $x_{s t}$ in regression $(G C T)$ vary over time but not across investors, the $m$ investor characteristics $z_{q h t}$ can vary across both the time dimension and the cross-section, respectively. It is interesting to notice that the structure of regression $(G C T)$ to which we henceforth refer to as the "GCT-regression model" is closely related to the structure of Ferson and Schadt's (1996) conditional performance measurement model. However, instead of being time-varying only, the conditional coefficients of the GCT-regression are allowed to vary over both the cross-section and the time.

\subsection{Relating the CalTime approach to the CrossReg technique}

The first step of the CrossReg approach involves estimating for each investor $h$ a time-series regression of $y_{h t}$ on $k$ market variables $x_{s t}(s=1, \ldots, k)$ as follows:

$$
y_{h t}=\beta_{0, h}+\beta_{1, h} x_{1 t}+\ldots+\beta_{k, h} x_{k t}+\varepsilon_{h, t}
$$

In the second step of the CrossReg approach, one then performs a cross-sectional regression of the coefficient estimate for $\beta_{s, h}(s \in\{0, \ldots, k\})$ from (7) on a set of $m$ investor characteristics $z_{q h}:$

$$
\hat{\beta}_{s, h}=c_{0, s}+c_{1, s} z_{1 h}+\ldots+c_{m, s} z_{m h}+w_{s, h} .
$$

\footnotetext{
${ }^{5}$ A Stata program which makes it simple to estimate several variants of the GCT-regression model $(G C T)$ is available from the authors upon request.
} 
By letting $z_{q h t}$ be constant over time (i.e. $z_{q h t}=z_{q h}$ ), the relation between the GCT-regression model and the CrossReg methodology may be stated as follows:

Proposition 3 In a balanced panel with $N$ investors and T time periods, OLS coefficient estimates for $c_{q, s}$ in (8) are identical to OLS coefficient estimates for $d_{q, s}$ in (GCT), i.e. $c_{q, s} \equiv d_{q, s}$ for $q=0,1, \ldots, m$ and $s=0,1, \ldots, k$.

Proof: See appendix.

However, because the second step regression of the CrossReg methodology only contains one single observation for each investor, it is impossible to estimate the standard errors for the coefficient estimates in (8) such that they are robust to cross-sectional dependence. According to Driscoll and Kraay (1998, p. 559) this is because "unlike in the time dimension, there is no natural ordering in the cross-sectional dimension [...] Thus it would appear that consistent covariance matrix estimation in models of a single cross section with spatial correlations will have to continue to rely on some prior knowledge of the form of these spatial correlations." Put differently, by dividing up the estimation procedure into two steps, the CrossReg approach abandons valuable information which can be used to ensure that the statistical results are valid even when cross-sectional dependence is present. ${ }^{6}$ In contrast, the GCT-regression model preserves any time-series information inherent in the data. This information advantage enables the GCT-regression model to produce standard error estimates that are robust to very general forms of cross-sectional and temporal dependence.

\section{Data}

The primary database used in this study includes the trades, monthly position statements, and demographic data of 41,719 individual investors. The data comes from a respectable European wholesale bank and covers the period from March 2000 to June 2005. In this section, we

\footnotetext{
${ }^{6}$ Moreover, the CrossReg approach outlined here also fails to adjust the second-stage standard errors for the fact that the dependent variable is estimated.
} 
describe the investor database and the procedure to compute the individual investors' portfolio returns.

\subsection{Description of the investor database}

The investors in our dataset constitute a random sample comprising $90 \%$ of the bank's private clients whose main account is denominated in CHF and whose financial wealth at the bank exceeded CHF 75,000 at least once prior to December 2003. ${ }^{7}$ Of the sampled investors, $81.3 \%$ live in Switzerland, 12.4\% are domiciled in Germany, 5.3\% reside in an other European country, and $1.0 \%$ live outside Europe. Most investors maintain a long-term relationship with the bank. As such, $81 \%$ of the accounts have been opened prior to December 1995. Nevertheless, almost $9 \%$ of the bank relationships in our sample have been established during the sample period. The attrition rate of the investors is relatively stable and amounts to about $0.2 \%$ per month. Yet, the "true" attrition rate is even lower since 2,924 out of 5,370 liquidated bank relationships have occured due to the account holder's death. The low monthly rate of account closings stands in some contrast to the attrition rates observed in comparable studies. Odean (1999), for example, reports that each month about $0.65 \%$ of the investors in his sample close their account at a large US discount brokerage house. Similarly, for a dataset on investors at a Swedish internet brokerage, Anderson (2004) finds that each month about $1.4 \%$ of the investors liquidate their account.

The average and median bank wealth of the investors in our database amount to CHF 221,520 and CHF 121,967, respectively. ${ }^{8}$ In this paper, we focus on the common stock investments of the investors. As can be inferred from Panel B in Table I, the median shareholding

\footnotetext{
${ }^{7}$ The bank did not want to provide a $100 \%$ sample for personal reasons. However, for all the sampled investors the database contains the entirety of the investors' accounts. A typical investor in our dataset holds two cash accounts and one security account. We are confident that the sampling criteria do not impact on the results. In particular, we deem it unlikely that the investors' stock returns are upward biased as a consequence of the CHF 75,000 threshold. The reason for this is that the sampled investors predominantly invest in Swiss stocks (see Table II) which lost 22\% of their value in the time period from March 2000 through December 2003.

${ }^{8}$ During the sample period, the USD-CHF exchange rate was quite volatile. On average, one USD cost about CHF 1.40. Therefore, the mean and median account value of the investors in our database correspond to about $\$ 158,230$ and $\$ 87,120$. On June 2005 (the sample end), the aggregated account value of the investors amounted to $\mathrm{CHF} 8.82 \mathrm{bn}$ which at the time was equal to $\$ 6.89 \mathrm{bn}$.
} 
investor in our database holds 2.60 distinct stocks worth CHF 45,660. However, both the distributions of the portfolio value and the number of stock holdings are skewed to the right. As such, a shareholding investor on average holds 3.98 stocks worth CHF 138,971.

Even though the sampled investors are relatively wealthy, only $27.5 \%$ hold month-end positions in common stocks. Hence, the proportion of equity owners is much lower in our sample than the $85.2 \%$ stockholder fraction reported by Barber and Odean (2000). However, the low proportion of shareholders in our dataset matches well with the results of Cocca and Volkart's (2006) equity ownership study for Switzerland. This study which may be compared to the US-american Survey of Consumer Finances (SCF) reveals that in spring 2000, 29.6\% of all Swiss households invested in common stocks. But since then, the overall fraction of shareholding households has declined to a mere $20.0 \%$ in spring $2006 .{ }^{9}$ However, in contrast to this result for the entirety of Swiss households, the equity ownership study also documents that for households with financial wealth in excess of CHF 100,000 the fraction of equity owners was above $30 \%$ over the entire sample period. Consistent with this, Figure 1 shows that in our database shareholders are wealthier on average than investors without stock holdings. Furthermore, Figure 1 reveals that the (median) bank wealth of the sampled investors increases with age. This pattern is in line with the findings of Poterba $(2001,2004)$ who observes that consumers accumulate financial assets while they are of working age but that they do not reduce financial assets thereafter. Together with the requirement that the investors' total account value has to exceed CHF 75,000 at least once prior to December 2003, this age-wealth relationship (Shorrocks, 1975) results in a disproportionate representation of old investors in the dataset. Correspondingly, Panel A of Table I documents that almost two thirds of the sampled investors are aged 60 or above in year 2005 .

The investors in our database heavily overweight Swiss stocks in their portfolios which confirms the well-known home-bias documented in the literature. Table II shows that the average and median portfolio share of $\mathrm{CHF}$ denominated stocks are $74.5 \%$ and $97.0 \%$, respectively.

\footnotetext{
${ }^{9}$ In Germany the fraction of shareholding households is even lower than in Switzerland. According to the Deutsches Aktieninstitut (2006), less than $10 \%$ of the German households invested in common stocks during the sample period.
} 
Amongst Swiss residents the overweight of Swiss stocks is even more pronounced. For this specific investor group, the average (median) proportion of CHF denominated stocks amounts to $80.8 \%(100 \%)$. It is popular to measure the degree of the home bias as 1 minus the weight invested in foreign countries scaled by the world market weight of foreign countries (e.g. see Kho, Stulz, and Warnock, 2006). Swiss stocks account for roughly 3\% of the world market. Therefore, the average Swiss resident exhibits a home bias of about $80 \%$ which corresponds in magnitude with the home bias observed by French and Poterba (1991) and others. Nevertheless, in absolute terms, the investors in our database diversify more internationally than do the investors of a large US discount broker. According to Bailey, Kumar, and Ng (2005) the average investor in their sample only holds $3.87 \%$ of her total portfolio value in foreign assets. ${ }^{10}$

To compute the monthly portfolio turnover of the investors, we employ the methodology developed by Barber and Odean (2000, p.781). Specifically, we define the portfolio turnover to be the average of the investor's buy and sell turnover during a month. ${ }^{11}$ For the average and median shareholder in our database, we observe a monthly turnover rate of $3.16 \%$ and $1.18 \%$, respectively. These turnover rates are less than half the size of those reported by Barber and Odean (2000) for a sample of private investors at a large US discount broker and almost six times smaller than those found by Anderson (2004) for a sample of Swedish online brokerage clients. Hence, the investors in our dataset are much more conservative in trading stocks than those in comparable studies. However, consistent with the findings of these studies, the investors in our database perform slightly more stock purchases $(73,098)$ than sales $(70,874)$, and the average value of stocks sold (CHF 29,400) is higher than the mean value of stocks bought (CHF 24,259).

A total of $41 \%$ of the transactions is in currencies other than CHF. These international trades are slightly smaller than transactions in CHF. For purchases (sales) of international stocks the average value is CHF 23,144 (CHF 25,675) which is CHF 1,971 (CHF 5,045) less than

\footnotetext{
${ }^{10}$ Bailey, Kumar, and $\mathrm{Ng}$ (2005) analyze the same dataset as do Barber and Odean $(2000,2001,2002)$, Ivkovic, Poterba, and Weisbenner (2005), Ivkovic and Weisbenner (2005), and Kumar and Lee (2006) among others.

${ }^{11}$ According to Barber and Odean (2000, p.781), the buy (sell) turnover in month $t$ is computed as the beginning-of-month $t$ market value of the shares purchased in month $t-1$ (sold in month $t$ ) divided by the total market value of the investor's stock portfolio at the beginning of month $t$. For details on how to compute the monthly portfolio turnover, also see Ivkovic, Sialm, and Weisbenner (2006).
} 
the corresponding transactions in CHF. Bailey, Kumar, and $\mathrm{Ng}$ (2005) who analyze the same dataset as Barber and Odean (2000) argue that the investors in their sample are very unlikely to diversify internationally by trading directly in foreign markets. In contrast, the investors in our database have to do so because most of the international stocks they trade are not listed on the Swiss stock exchange. As a consequence, investors without a cash account denominated in the transaction currency have to pay two bid-ask spreads, one for the currency conversion and one for the stock transaction. On average, transaction costs for purchases and sales of international stocks are therefore significantly higher than for Swiss stocks. As a result, it might well be that the pronounced home bias of private investors can partially be explained by the high transaction costs of international stock trades.

Roughly $45 \%$ of the sampled investors are female. Amongst shareholders, the proportion of women is slightly lower but nevertheless amounts to $37 \%$. As a result, the fraction of female account holders in our dataset is comparable to the $50 \%$ share of women observed in samples from the People's Republic of China (e.g. see Feng and Seasholes, 2004a, 2006). In contrast, women are typically underrepresented in datasets on investors from discount and online brokerage houses (see e.g. Barber and Odean, 2001; Dorn and Huberman, 2005; Anderson, 2004). We observe a similar pattern in our database when looking at the 1,892 investors with online banking transactions. Amongst this specific investor group, the proportion of female investors is only $23.2 \%$. Tables I and II which contrast the investment practices of men and women on an unconditional basis highlight possible gender differences in the investment behavior of private investors. For instance, women tend to weight CHF denominated stocks more heavily in their portfolios than men. According to Table II this pattern is robust amongst different investor groups and it is particularly pronounced for non-Swiss investors. Overall, the weight of Swiss stocks is $7.8 \%$ higher in the stock portfolios of women than in those of men. This finding conflicts with the results of Feng and Seasholes (2006) who report that in the People's Republic of China the home bias is similar across gender. Admittedly, however, we do not have an explanation for the large weight of Swiss stocks in the portfolios of non-Swiss women compared to the portfolio weight of Swiss stocks for non-Swiss men. In line with the results of Feng and Seasholes (2006), men tend to hold bigger and more diversified stock portfolios than women. 
In addition and consistent with Barber and Odean (2001), women turn over their portfolio more slowly than men and, on average, perform about $35 \%$ less stock trades than men. Somewhat surprisingly, however, the median value of both stock purchases and sales is higher for women than for men.

\subsection{Return computations}

We use Thomson Datastream (TDS) to retrieve monthly time-series of stock prices and dividends for all common stocks that are held by the investors. ${ }^{12}$ Overall, the investors hold a total of 3,098 distinct stocks of which 1,182 are listed in the United States, 522 in Germany, and 332 in Switzerland. Based on monthly time-series of 61 exchange rates relative to the CHF, we compute the stocks' percentage monthly gross return in CHF as follows:

$$
R_{i, t}^{g r}=100\left(\frac{P_{i, t}+D_{i, t}}{P_{i, t-1}} \frac{S_{t}^{x}}{S_{t-1}^{x}}-1\right)
$$

where $P_{i, t}$ denotes the adjusted closing price of stock $i$ in month $t$ and $D_{i, t}$ contains the sum of dividends paid from stock $i$ during month $t$. Both $P_{i, t}$ and $D_{i, t}$ are expressed in local currency. Finally, $S_{t}^{x}$ refers to the end-of-month $t$ exchange rate (in price notation) between the currency in which the stock is denominated and the CHF.

To compute the gross return of the individual investors' stock portfolios we apply the methodology developed by Barber and Odean (2000). Specifically, for each investor $h$ we estimate the month $t$ gross return [in \%] as the value-weighted average return of the beginningof-month stock holdings:

$$
R_{h, t}^{g r}=\sum_{i=1}^{s_{h, t-1}} w_{i, t-1} R_{i, t}^{g r}
$$

\footnotetext{
${ }^{12}$ We refer to "common stocks" as assets with TDS datatype TYPE being equal to EQ. We use this simple definition for common stocks even though Ince and Porter (2004) report that numerous TDS identifiers with TYPE=EQ are closed end funds, REITs, or ADRs rather than common stocks. However, for our dataset the conformity between datatype TYPE in TDS and the bank's own asset classification scheme is very high. For position holdings with TYPE=EQ, the bank also classifies the asset to be an EQUITY in $99.49 \%$ of the cases. Similarly, conditional on being in the universe of TDS, $99.68 \%$ of the EQUITY position holdings are of TYPE EQ in Thomson Datastream. Overall, TDS contains the closing prices and dividends for $93.79 \%$ of all the investors' EQUITY position holdings.
} 
where $w_{i, t-1}$ is the beginning-of-month $t$ weight of stock $i$ in the portfolio of investor $h$. It is computed as the beginning-of-month $t$ position value (in CHF) of stock $i$ divided by the aggregated position value (in CHF) of all $s_{h, t-1}$ stock holdings at the time. When computing $R_{h, t}^{g r}$ we make the same simplifying assumptions as do Barber and Odean (2000). Specifically, we presume that all the investors' stock transactions take place on the last day of the month. Thus, we do not consider return components earned between the purchase date of a stock and the end of the month, but we include the stock returns from the actual sale date to the end of the month. Furthermore, with the exception of short-term trades that result in position holdings at the end of a calendar month, we ignore any intramonth trading activity of the investors. Barber and Odean (2000) demonstrate that these simplifying assumptions only cause minor differences in the return calculations even if the portfolio turnover of the investors is high. In our dataset, the turnover rate of the investors is low. Therefore, our return calculations should only marginally be affected by these assumptions.

For each stock transaction, we estimate the transaction costs as the sum of the commissions and a bid-ask spread component. While the bank provides us with the effective commissions (in $\mathrm{CHF}$ ) of the transactions, we have to estimate the bid-ask spread component of the transaction costs by our own. To do so, we retrieve the stocks' daily bid and ask prices from TDS and compute the bid-ask spread $\left(s p r_{i, \tau}\right)$ component of the transaction costs for stock $i$ on day $\tau$ as

$$
s p r_{i, \tau}=\frac{P_{i, \tau}^{b}-P_{i, \tau}^{s}}{P_{i, \tau}^{b}+P_{i, \tau}^{s}}
$$

where $P_{i, \tau}^{b}$ and $P_{i, \tau}^{s}$ denote the bid and ask price of stock $i$ on day $\tau$, respectively. We use quoted spreads rather than the price impact measure proposed by Barber and Odean (2000, p. 780) because the stock transactions of the investors in our database are small compared to the trades of institutional investors. Therefore, we expect stock prices to be virtually unaffected by the transactions of the sampled investors. Furthermore, unlike transactions of institutional investors which are often executed inside the quoted spreads this is much less so for retail investors (Keim and Madhavan, 1998). ${ }^{13}$ Across all trades, the average (median) total transaction cost of a stock

\footnotetext{
${ }^{13}$ However, if the bid and ask prices are not available from TDS, we compute the bid-ask spread component of
} 
purchase amounts to $1.48 \%(1.19 \%)$ for Swiss stocks, and $2.00 \%$ (1.46\%) for foreign stocks. For stock sales, the average (median) transaction costs are 1.69\% (1.19\%) for Swiss stocks, and $3.17 \%(1.80 \%)$ for foreign stocks.

For each investor $h$, we compute the trade weighted average transaction cost of all purchases $\left(c_{i, t}^{h, b}\right)$ and sales $\left(c_{i, t}^{h, s}\right)$ of stock $i$ in month $t$. Further, we consider the fact that the sampled investors sometimes do not purchase and sell complete stock positions but rather they trade fractions of existing holdings. Therefore, we slightly adjust Barber and Odean's (2000, p. 782) methodology of how to compute the month $t$ net return [in \%] of stock $i$ in the portfolio of investor $h$ as follows:

$$
\left(1+R_{i, t}^{h, n e t} / 100\right)=\left(1+R_{i, t}^{C H F} / 100\right) \frac{\left(N_{i, t}^{h}-c_{i, t}^{h, s} N_{i, t}^{h, s}\right)}{\left(N_{i, t}^{h}+c_{i, t-1}^{h, b} N_{i, t-1}^{h, b}\right)}
$$

In (12), $N_{i, t}^{h}$ denotes the beginning-of-month $t$ number of stocks $i$ in the portfolio of investor $h$, $N_{i, t}^{h, s}$ refers to the number of stocks sold in month $t$, and $N_{i, t-1}^{h, b}$ is the number of stocks bought in month $t-1 .{ }^{14}$ If an investor trades the entire stock position in a given month, our definition of $R_{i, t}^{h, n e t}$ in expression (12) is equal to the one used by Barber and Odean (2000). However, when only parts of an existing stock position are bought or sold, then the stock's net return $\left(R_{i, t}^{h, n e t}\right)$ is closer to its gross return $\left(R_{i, t}^{g r}\right)$. By using (12), we then obtain the month $t$ net return [in \%] of investor $h$ 's stock portfolio $\left(R_{h, t}^{n e t}\right)$ as

$$
R_{h, t}^{n e t}=\sum_{i=1}^{s_{h, t-1}} w_{i, t-1} R_{i, t}^{h, n e t}
$$

Finally, we also compute for each investor the monthly gross and net excess return [in \%] as

$$
y_{h, t}^{g r}=R_{h, t}^{g r}-R_{f, t} \quad \text { and } \quad y_{h, t}^{n e t}=R_{h, t}^{n e t}-R_{f, t}
$$

where $R_{f, t}$ refers to the month $t$ return [in \%] on a short-term Eurodeposit in CHF obtained

the transaction costs as proposed by Barber and Odean (2000, p. 780).

${ }^{14}$ To properly account for stock splits, we use adjusted values for $N_{i, t}^{h}, N_{i, t}^{h, s}$, and $N_{i, t-1}^{h, b}$. 
from TDS. ${ }^{15}$

\section{Empirical Analysis}

\subsection{An illustration of Propositions 1-3}

We begin with an exact empirical validation of Propositions 1 through 3. Since all the propositions rely on the assumption of a balanced investor panel with two investor groups that are constant over time, it seems natural to compare the investment performance of women and men. Therefore, we follow Barber and Odean (2001, p. 277) by hypothesizing that after accounting for transaction costs the investment performance of men should be worse than that of women because "men, who are more overconfident than women, trade more than women". We restrict the analysis to a balanced panel of 2,724 male and 1,432 female investors with stock holdings all over the sample period from March 2000 through June 2005.

The CalTime approach. Using the traditional CalTime approach, we test whether or not women outperform men by evaluating the coefficient estimate for the intercept term $\alpha_{\Delta}$ in the time-series regression

$$
\Delta y_{t}^{n e t}=\alpha_{\Delta}+\beta_{\Delta} \mathrm{SPI}_{t}+\gamma_{\Delta} \operatorname{World}_{t}+s_{\Delta} \mathrm{SMB}_{t}+h_{\Delta} \mathrm{HML}_{t}+\epsilon_{t}
$$

Here, $\mathrm{SPI}_{t}$ is the monthly excess return of the Swiss Performance Index and World $\mathrm{d}_{t}$ refers to the monthly excess return of the MSCI World total return index orthogonalized by $\mathrm{SPI}_{t}$. The $\mathrm{SMB}_{t}$ factor denotes the month $t$ return of a zero-investment portfolio which is long in Swiss small caps and short in Swiss large capitalization stocks. Finally, $\mathrm{HML}_{t}$ refers to the monthly return difference between Swiss high and low book-to-market stocks. ${ }^{16}$

\footnotetext{
${ }^{15}$ The Datastream-Mnemonic of the $R_{f, t}$ time-series used in this study is SBWSF3L.

${ }^{16}$ To compute excess returns, we use the return on short-term Eurodeposits in CHF as a proxy for the risk-free investment. The data source is TDS and the Datastream-Mnemonic is SBWSF3L. The $\mathrm{SMB}_{t}$ factor is obtained as the return differential of the Vontobel-Datastream Small Cap Index and the Swiss Market Index (SMI). Finally, the $\mathrm{HML}_{t}$ factor returns are taken from Ken French's website:

http://mba.tuck.dartmouth.edu/pages/faculty/ken.french/data_library.html.
} 
The dependent variable, $\Delta y_{t}^{n e t}$, in regression (15) is the monthly net return of a zeroinvestment portfolio which is long in the aggregate stock portfolio of women and short in the corresponding portfolio of men. It is computed as

$$
\Delta y_{t}^{n e t}=y_{w t}^{n e t}-y_{m t}^{n e t}
$$

with $y_{w t}^{n e t}=\frac{1}{N_{w t}} \sum_{h=1}^{N_{t}} \operatorname{Woman}_{h} \times y_{h t}^{n e t}$ and $y_{m t}^{n e t}=\frac{1}{N_{m t}} \sum_{h=1}^{N_{t}}\left(1-\operatorname{Woman}_{h}\right) \times y_{h t}^{n e t}$

where $N_{w t}$ and $N_{m t}$ refer to the month $t$ number of female and male investors, and $N_{t}=$ $N_{w t}+N_{m t}$. Woman is a dummy variable which is one for women and zero for men and $y_{h t}^{\text {net }}$ is the month $t$ net excess return of investor $h$ whose computation has been described in Section 3.2.

The results of estimating the CalTime regression in (15) with OLS are displayed in Table III. The t-values reported in the two columns with SE-type "NW87" and "NW87a" rely on Newey and West (1987) standard errors with and without degree-of-freedom correction, respectively. These t-values are heteroscedasticity and autocorrelation (up to three lags) consistent. The estimate for the intercept term $\alpha_{\Delta}$ is positive and (weakly) significant in all CalTime columns, and we therefore conclude that after accounting for transaction costs, women outperform men by about $1.07 \%$ per year on average. This result is consistent with the findings of Barber and Odean (2001).

The GCT-regression model. Propositions 1 and 2 claim that estimating time-series regression (15) with Newey and West (1987) standard errors (without degree-of-freedom correction) yields identical results as estimating the following investor-level pooled OLS regression with Driscoll and Kraay (1998) standard errors:

$$
\begin{aligned}
y_{h t}^{\text {net }} & =\alpha_{m}+\beta_{m} \mathrm{SPI}_{t}+\gamma_{m} \operatorname{World}_{t}+s_{m} \mathrm{SMB}_{t}+h_{m} \mathrm{HML}_{t} \\
& +\alpha_{\Delta} \operatorname{Woman}_{h}+\beta_{\Delta} \mathrm{SPI}_{t} \times \operatorname{Woman}_{h}+\gamma_{\Delta} \operatorname{World}_{t} \times \operatorname{Woman}_{h} \\
& +s_{\Delta} \mathrm{SMB}_{t} \times \operatorname{Woman}_{h}+h_{\Delta} \mathrm{HML}_{t} \times \operatorname{Woman}_{h}+v_{h t}
\end{aligned}
$$


By exemplifying that the coefficient estimates and t-stats of columns "CalTime NW87a" and "POLS DK98" in Table III coincide, we empirically demonstrate the validity of Propositions 1 and 2 .

In contrast to Driscoll and Kraay (1998) standard errors which are robust to very general forms of cross-sectional and temporal dependence, Arellano's (1987) panel-robust standard errors only allow for correlation within clusters but assume independence between the clusters (e.g. individuals). Thus, in Table III the t-values presented in column "POLS A87" are biased when cross-sectional dependence is present. Since cross-sectional dependence is likely to occur in microeconometric panels (e.g. Feng and Seasholes, 2004a; Dorn, Huberman, and Sengmueller, 2005; Kumar and Lee, 2006), one should be careful with drawing conclusions from regression models which are based on the assumption of independence between subjects. Indeed, in this specific case we find that panel-robust t-values for the market level variables and the Woman dummy are much higher than those in column "POLS DK98". For instance, accounting for cross-sectional dependence in the data scales down the t-value of the Woman dummy, which is of key interest for testing whether or not women outperform men, from $t_{\text {Woman }}^{A 87}=4.347$ to $t_{\text {Woman }}^{D K 98}=2.021$.

The CrossReg approach. In order to reproduce the coefficient estimate for $\alpha_{\Delta}$ in (17) using the CrossReg approach, we first obtain for each investor $h$ the risk-adjusted performance $\hat{\alpha}_{h}$ from the four-factor time-series regression

$$
y_{h t}^{n e t}=\alpha_{h}+\beta_{h} \mathrm{SPI}_{t}+\gamma_{h} \operatorname{World}_{t}+s_{h} \mathrm{SMB}_{t}+h_{h} \mathrm{HML}_{t}+\epsilon_{h t} .
$$

In the second step, we then test whether or not women outperform men by regressing $\hat{\alpha}_{h}$ from (18) on the Woman dummy:

$$
\hat{\alpha}_{h}=c_{0}+c_{1} \operatorname{Woman}_{h}+w_{h}
$$

Table III, column "OLS W80", contains the results from estimating (19) with heteroscedasticity consistent standard errors. As predicted by Proposition 3, the coefficient estimate for $c_{1}$ coincides with that for $\alpha_{\Delta}$ in the GCT-regression (17). However, in contrast to the traditional 
calendar time portfolio approach which replicates Driscoll and Kraay (1998) standard errors, the CrossReg methodology can at best be used to reproduce panel-robust standard errors for the GCT-regression in (17). Therefore, statistical inference from the CrossReg approach is valid if and only if cross-sectional dependence is absent. However, when cross-sectional dependence is likely to be inherent in the data, then the CrossReg methodology should not be applied. This is because the two-step algorithm which forms the basis of the CrossReg methodology forgoes valuable time-series information which can otherwise be used to ensure validity of the statistical results even when cross-sectional dependence is present.

\subsection{Time-varying investor groups and unbalanced panels}

So far our analysis is limited to a balanced panel with two investor groups that are constant over time. In most empirical work, however, these assumptions will not be met. Therefore, we replicate the analysis from Section 4.1 by analyzing an unbalanced panel of all 7,140 male and 4,200 female investors with end-of-month positions in common stocks. As before, we follow Barber and Odean (2001) by hypothesizing that after accounting for transaction costs, women outperform men.

In Table IV, columns labeled with "CalTime", we present the results for the traditional CalTime approach. While the first "CalTime" column contains the coefficient estimates and t-values from estimating regression (15) with $\Delta y_{t}^{n e t}=y_{w t}^{n e t}-y_{m t}^{n e t}$ as the dependent variable, the second "CalTime" column presents the results of estimating (15) with $y_{m t}^{\text {net }}$ as the dependent variable. Both $\Delta y_{t}^{\text {net }}$ and $y_{m t}^{\text {net}}$, respectively, are obtained from equation (16). As for the balanced panel considered in Section 4.1 and consistent with Barber and Odean (2001), we find that after accounting for transaction costs, women outperform men by a significant return difference of $1.14 \%$ per year on average.

In an unbalanced panel with time-varying investor groups, the traditional CalTime approach does not weight each observation equally (Loughran and Ritter, 2000). Therefore, estimating the GCT-regression (17) with OLS turns out to be inappropriate for replicating the results 
of the calendar time portfolio approach. From Table IV this is apparent by observing that the coefficient estimates and t-stats in column "POLS" do not match those in the "CalTime" columns. However, even for the general case of an unbalanced panel with time-varying investor groups it is possible to reproduce the results of the traditional CalTime approach by aid of the GCT-regression model in (17). But now we have to explicitly adopt the observation weighting scheme of the CalTime approach and estimate (17) with weighted least squares (WLS) rather than with OLS. We therefore set the observation weights equal to ${ }^{17}$

$$
\omega_{h t}= \begin{cases}N_{w t}^{-1}, & \text { if } \operatorname{Woman}_{h}=1 \\ N_{m t}^{-1}, & \text { otherwise }\end{cases}
$$

In Table IV, columns labeled with "PWLS", we present the WLS estimation results of regression (17). As for the balanced panel case, there is evidence for cross-sectional dependence in the data: Estimating (17) with Driscoll-Kraay standard errors produces t-values for the market variables and the Woman dummy which are much smaller (in absolute terms) than those from estimating the GCT-regression (17) with panel-robust standard errors.

Although column "PWLS DK98" shows that the results of the traditional CalTime approach may be reproduced with a WLS regression on the investor level, we can not find an econometric reason why employing the weighting scheme in (20) should yield more appropriate results than estimating (17) with OLS. On the contrary, the weighting scheme in (20) has even been criticized by Loughran and Ritter (2000, p.363) who argue that "in general, tests that weight firms equally should have more power than tests that weight each time period equally". As a result, estimating the GCT-regression model in (17) with OLS rather than with WLS naturally resolves Loughran and Ritter's (2000) critique.

\footnotetext{
${ }^{17}$ Alternatively, we could also multiply both sides of regression (17) with $\sqrt{\omega_{h t}}$ and estimate the transformed regression model with OLS.
} 


\subsection{Multivariate investor characteristics and performance measurement}

In this section, we make use of the GCT-regression model's capability to handle continuous and multivariate investor characteristics. Thereby, we utilize the GCT-regression model to verify some of the most prominent hypotheses on the performance of private investors. All the regressions analyzed in this section embody the following structure:

$$
y_{h, t}=\left(\mathbf{z}_{h t} \otimes \mathbf{x}_{t}\right) \mathbf{d}+v_{h t}
$$

where, depending on the specific hypothesis, $y_{h, t}$ denotes the investors' gross excess return $\left(y_{h, t}^{g r}\right)$ or net excess return $\left(y_{h, t}^{n e t}\right)$. While the investor characteristics contained in vector $\mathbf{z}_{h t}$ vary among the models, the composition of the market variables in vector $\mathbf{x}_{t}$ remains unchanged. As in Sections 4.1 and 4.2, we compute the risk-adjusted performance of the investors by specifying $\mathbf{x}_{t}=\left[\begin{array}{lllll}1 & \mathrm{SPI}_{t} & \text { World }_{t} & \mathrm{SMB}_{t} & \mathrm{HML}_{t}\end{array}\right]$.

The first hypothesis to be addressed is derived from Barber and Odean (2000) who find that "investors who hold common stocks directly pay a tremendous performance penalty for active trading”. Following Barber and Odean (2000) we therefore expect that ${ }^{18}$

H1a The portfolio turnover rate is unrelated to the gross performance of an investor.

H1b In contrast, the net performance of an investor decreases with the portfolio turnover.

To empirically examine Hypothesis 1, we estimate regression (21) with $\mathbf{z}_{h t}$ being specified as $\mathbf{z}_{h t}=\left[\begin{array}{ll}1 & \mathrm{TO}_{h, t}\end{array}\right]$ where $\mathrm{TO}_{h, t}$ is the month $t$ turnover of investor $h$ 's stock portfolio. From Table V, columns labeled with "H1a" and "H1b", it is apparent that both parts of Hypothesis 1 are confirmed. Specifically, the monthly stock turnover has no statistically significant impact on the gross performance (H1a), but an investor who completely redeploys her stock portfolio lowers the risk-adjusted net return by a sizable and significant $3.69 \%$ on average (H1b).

Our second hypothesis is based on Barber and Odean (2001) who report that "since men

\footnotetext{
${ }^{18}$ The hypotheses we state in this section are alternative hypotheses. Therefore, when we "confirm" hypothesis $\mathrm{XYZ}$, we actually mean that the null hypothesis to hypothesis XYZ has to be rejected and thus hypothesis XYZ is accepted.
} 
are more overconfident than women, men will trade more and perform worse than women." We therefore test the following hypothesis:

H2a The net performance of men is worse than that of women.

H2b Men underperform women on a net return basis because they trade more than women.

By specifying vector $\mathbf{z}_{h t}$ as $\mathbf{z}_{h t}=\left[\begin{array}{lll}1 & \mathrm{Woman}_{h}\end{array}\right]$ and estimating regression (21) with the investors' net excess return $\left(y_{h, t}^{n e t}\right)$ as the dependent variable, we find (weak) evidence in favor of hypothesis H2a. As such, column "H2a" of Table V shows that the risk-adjusted net return of the average women in our dataset exceeds that of a typical men by $1.06 \%$ per year $(=12 \times 0.088 \%)$. If hypothesis $\mathrm{H} 2 \mathrm{~b}$ holds true and women really outperform men simply

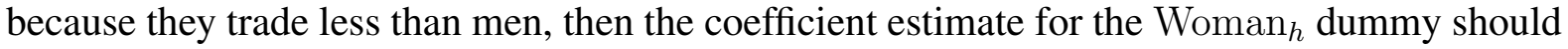
become insignificant when the monthly portfolio turnover is included in the regression. To empirically validate hypothesis H2b, we therefore re-estimate the GCT-regression model (21) with $\mathbf{z}_{h t}$ being specified as $\mathbf{z}_{h t}=\left[\begin{array}{lll}1 & \text { Woman }_{h} & \mathrm{TO} \\ h, t\end{array}\right]$. Column "H2b" of Table V, reveals that augmenting vector $\mathbf{z}_{h t}$ with the investors' portfolio turnover indeed results in an insignificant coefficient estimate for the $\operatorname{Woman}_{h}$ dummy. We therefore conclude that our data (weakly) support Hypothesis 2.

For our third conjecture, we rely on the findings of Barber and Odean (2002) who show that online investors "trade more actively, more speculatively, and less profitably" than phone-based investors. Therefore, we hypothesize that

H3 Both the gross and net performance of online investors is lower than that of phone-based investors.

In order to verify this hypothesis, we specify vector $\mathbf{z}_{h t}$ as $\mathbf{z}_{h t}=\left[\begin{array}{ll}1 & \text { Online }_{h}\end{array}\right]$ where Online is a dummy variable with value one for investors who perform stock transactions over an online banking account, and zero otherwise. The results from estimating (21) with $\mathbf{z}_{h t}=\left[\begin{array}{ll}1 & \text { Online }_{h}\end{array}\right]$ strongly confirm the conjecture. Specifically, columns "H3" of Table V reveal that on average the risk-adjusted gross (net) return of an online investor is a remarkable and highly significant $2.33 \%(3.25 \%)$ per year lower than for a phone-based investor. 
The last hypothesis to be addressed in this section is taken from Ivkovic, Sialm, and Weisbenner (2006). They report that "skilled investors can exploit information asymmetries by concentrating their portfolios in the stocks about which they have favorable information." We therefore conjecture that

H4a Both the gross and net performance of an investor are negatively related to the number of stocks in her portfolio.

We test hypothesis H4a by defining $\mathbf{z}_{h t}$ as $\mathbf{z}_{h t}=\left[\begin{array}{ll}1 & \mathrm{NS} \\ h, t\end{array}\right]$ where $\mathrm{NS}_{h, t}$ is the beginning-ofmonth $t$ number of stocks in the portfolio of investor $h$. From Table V, columns labeled with "H4a", one can see that the coefficient estimate for $\mathrm{NS}_{h, t}$ is negative and significant. Thus, we can confirm hypothesis H4a. However, the latter hypothesis is just a part of the story in Ivkovic, Sialm, and Weisbenner (2006). In particular, the authors also take into consideration that "fixed costs of trading stocks make it uneconomical for households with limited wealth to hold a large number of securities directly. Moreover, it is likely that some wealthy households might have greater access to information and might possess information processing skills superior to those prevailing among households with smaller accounts, prompting a certain fraction of wealthy investors to concentrate their portfolios in a few investments." Therefore, we refine hypothesis H4a as follows:

H4b Due to fixed costs of trading stocks, concentrated investors perform particularly well if their portfolio value is large.

To empirically examine this conjecture, we augment vector $\mathbf{z}_{h t}$ by the natural logarithm of the investors' beginning-of-month $t$ portfolio value $\mathrm{V}_{h, t}$. According to hypothesis $\mathrm{H} 4 \mathrm{~b}$ we would expect that the coefficient estimate for $\mathrm{V}_{h, t}$ is positive and statistically significant. However, as can be seen from Table V, columns labeled with "H4b", estimating regression (21) with $\mathbf{z}_{h t}$ being specified as $\mathbf{z}_{h t}=\left[\begin{array}{lll}1 & \mathrm{NS}_{h, t} & \mathrm{~V}_{h, t}\end{array}\right]$ yields a negative and insignificant coefficient estimate for $\mathrm{V}_{h, t}$. As a result, for the investors in our database hypothesis $\mathrm{H} 4 \mathrm{~b}$ can not be verified. ${ }^{19}$

\footnotetext{
${ }^{19}$ As an alternative test for hypothesis $\mathrm{H} 4 \mathrm{~b}$, we specify vector $\mathbf{z}_{h t}$ as $\mathbf{z}_{h t}=\left[\begin{array}{llll}1 & \mathrm{NS}_{h, t} & \mathrm{~V}_{h, t} & \mathrm{NSV} \\ h, t\end{array}\right]$ and test if the coefficient estimate for the interaction term $\mathrm{NSV}_{h, t}=\mathrm{NS}_{h, t} * \mathrm{~V}_{h, t}$ is negative and significant. However, the coefficient estimate for $\mathrm{NSV}_{h, t}$ is positive and insignificant. Thus, we must again reject hypothesis $\mathrm{H} 4 \mathrm{~b}$.
} 
Our empirical analysis up to this point was restricted to a sequential test of some of the most prominent hypotheses on the performance of private investors. As a robustness check for the (supported) hypotheses at hand, we now want to examine them simultaneously. Therefore, we specify vector $\mathbf{z}_{h t}$ as $\mathbf{z}_{h t}=\left[\begin{array}{lllll}1 & \mathrm{TO}_{h, t} & \operatorname{Woman}_{h} & \text { Online }_{h} & \mathrm{NS}_{h, t}\end{array}\right]$.

To commence the multi-hypotheses analysis, we first estimate the GCT-regression model (21) with the investors' gross excess return $\left(y_{h, t}^{g r}\right)$ as the dependent variable. This allows us to simultaneously validate hypotheses H1a, H3, and H4a. Even though it follows from Table V, column "All $\left(y_{h, t}^{g r}\right)$ ", that the coefficient estimate for variable $\mathrm{NS}_{h, t}$ is just weakly significant, it is nevertheless interesting to notice that the results of this multi-hypotheses test turn out to be very similar to those of the single hypothesis checks performed before. In the second part of our multi-hypotheses analysis, we re-estimate regression (21) with the investors' net excess return $\left(y_{h, t}^{n e t}\right)$ as the dependent variable. The results of this simultaneous test of hypotheses $\mathrm{H} 1 \mathrm{~b}, \mathrm{H} 2 \mathrm{a}, \mathrm{H} 2 \mathrm{~b}, \mathrm{H} 3$, and H4a are displayed in column "All $\left(y_{h, t}^{n e t}\right)$ " of Table V. Although being slightly less significant than the single hypothesis checks discussed above, the results of this test nonetheless fully support the previous assertions. We therefore conclude that except hypothesis $\mathrm{H} 4 \mathrm{~b}$, our empirical analysis in this section provides further evidence for some of the most common hypotheses on the performance of private investors.

\subsection{Does cross-sectional dependence matter?}

In two recent articles, Ivkovic and Weisbenner (2005) and Massa and Simonov (2006) claim that the local stock investments of private investors outperform their remote stock holdings. However, Seasholes and Zhu (2005) challenge the results of these studies because they fail to account for cross-sectional dependence in the data. To explicitly allow for spatial correlation, Seasholes and Zhu (2005) who use the same dataset as Ivkovic and Weisbenner (2005) employ the CalTime approach to investigate whether or not there is information in the local portfolio choices of private investors. By performing a "back-of-the-envelope calculation", Seasholes and Zhu find that their standard error estimates are approximately six times larger than those of Ivkovic and Weisbenner (2005) who estimate cross-sectional regressions. As a result, they 
conclude "that living near a company does not endow an investor with value-relevant information."

But is cross-sectional dependence really an issue? In order to address this question, we want to investigate the following hypothesis:

H5a Swiss residents' investments in Swiss stocks outperform those of non-Swiss residents.

H5b However, this holds true if and only if one does not account for cross-sectional dependence in the data.

In order to test Hypothesis 5, we estimate several variants of regression (21). In doing so we use the investors' monthly gross excess return $\left(y_{h, t}^{g r}\right)$ as the dependent variable and specify vector $\mathbf{z}_{h t}$ as $\mathbf{z}_{h t}=\left[\begin{array}{llll}1 & \text { Swiss }_{h} & \mathrm{WCHF}_{h t} & \mathrm{SWC}_{h t}\end{array}\right]$. Here, $\mathrm{Swiss}_{h}$ is a dummy variable which is 1 for Swiss residents and zero otherwise and $\mathrm{WCHF}_{h t}$ refers to the beginning-of-month $t$ weight of Swiss stocks in the portfolio of investor $h$. If Hypothesis 5 is appropriate, then the coefficient estimate for the interaction variable $\mathrm{SWC}_{h t}=\mathrm{Swiss}_{h} * \mathrm{WCHF}_{h t}$ should be positive (H5a). Moreover, if regression (21) is estimated with OLS or panel-robust standard errors, then the coefficient estimate for variable $\mathrm{SWC}_{h t}$ should be significantly different from zero. In contrast, estimating regression (21) with Driscoll and Kraay (1998) standard errors should result in an insignificant coefficient estimate for variable $\mathrm{SWC}_{h t}(\mathrm{H} 5 \mathrm{~b})$.

As can be seen from the first three columns of Table VI, the investors in our database fully support Hypothesis 5. Besides being positive, the coefficient estimate for variable $\mathrm{SWC}_{h t}$ is highly significant when cross-sectional dependence is ignored (columns "OLS" and "A87"). ${ }^{20}$ However, as postulated by hypothesis $\mathrm{H} 5 \mathrm{~b}$, the coefficient estimate for $\mathrm{SWC}_{h t}$ indeed becomes insignificant when cross-sectional correlation is accounted for (column "DK98”). Put differently, by allowing for cross-sectional dependence we do not find evidence for an information advantage of Swiss residents compared to foreigners when investing in Swiss stocks.

Interestingly, cross-sectional dependence does not inflate all t-stats by the same amount. From Table VI, columns "A87" and "DK98", we can see that the panel robust t-value for vari-

\footnotetext{
${ }^{20}$ Note that estimating regression (21) with panel robust standard errors essentially replicates the results of the CrossReg approach. See Section 2.4 for details.
} 
able $\mathrm{SWC}_{h t}$ in column "A87" is "only" two and a half times as large as the cross-sectional dependence consistent t-value in column DK98. In contrast, the panel robust t-value for variable $\mathrm{WCHF}_{h t}$ is almost five times larger than the corresponding Driscoll-Kraay t-stat.

In the last three columns of Table VI, we present the results from a joint test of hypotheses $\mathrm{H} 1$ through H5. Augmenting vector $\mathbf{z}_{h t}$ with the investor characteristics considered in Section 4.3 does not significantly impact on the coefficient estimates and t-stats for the variables of Hypothesis 5. In particular, we find that the coefficient estimate for the interaction term $\mathrm{SWC}_{h t}$ is again positive and highly significant when cross-sectional dependence is ignored. However, when cross-sectional correlation is accounted for, then the respective coefficient estimate becomes insignificant. Like before, we find that the t-values of columns "OLS" and "A87" are up to five times higher than the spatial correlation consistent t-values in column "DK98". Thus, we conclude that erroneously ignoring cross-sectional dependence inherent in the data can lead to severely biased statistical results.

\section{Conclusion}

In this paper, we present a generalization of the calendar time portfolio approach which can easily be implemented in empirical studies. Our methodology is based on the estimation of a linear regression model on the investor or firm level. Therefore, it is straightforward to include continuous and multivariate investor or firm characteristics in the analysis. We show both theoretically and empirically that our "GCT-regression model" is capable to perfectly reproduce the results of the CalTime approach. Furthermore, since it relies on the nonparametric covariance matrix estimator of Driscoll and Kraay (1998), the GCT-regression model assures that its statistical results are heteroscedasticity consistent and robust to very general forms of temporal and cross-sectional dependence.

The GCT-regression model resolves or at least mitigates several weaknesses of the calendar time portfolio methodology. For example, Loughran and Ritter (2000, p. 363) argue against the CalTime approach since it has low power to identify market anomalies. The reason for this is, 
that "in general, tests that weight firms equally should have more power than tests that weight each time period equally." By estimating the GCT-regression model with ordinary least squares (OLS), all observations are equally weighted. As a result, the GCT-regression model provides an elegant way to remedy the critique of Loughran and Ritter (2000).

Moreover, Lyon, Barber, and Tsai (1999, p. 198) report that the calendar time portfolio approach is susceptible to produce misspecified test statistics in nonrandom samples. Their explanation for this finding is that although it is possible "to control for many sources of misspecification, ultimately, the misspecification that remains can be attributed to the inability of firm size and book-to-market ratio to capture all of the misspecification of the Capital Asset Pricing Model." Because of its capability to handle continuous and multivariate investor or firm characteristics, the GCT-regression model establishes a potential solution to this misspecification issue. Specifically, to assure that the test statistics in a nonrandom sample are wellspecified, a researcher might want to include certain investor or firm specific control variables in the GCT-regression model.

Our analysis also reveals that the CrossReg approach is at risk of producing seriously biased statistical results when it is used to analyze microeconometric panel data. The reason for this deficiency of the CrossReg methodology is its incapability to estimate spatial correlation consistent standard errors. In the empirical part of the paper we investigate by how much cross-sectional dependence impacts on the statistical results. Analyzing a new, unique dataset on 41,719 individual investors at a respectable European wholesale bank from March 2000 through June 2005, we find that t-values that are based on the assumption of cross-sectional independence are often three and more times higher than t-values that are based on DriscollKraay standard errors (which are spatial correlation consistent). Therefore, we conclude that cross-sectional dependence indeed can have severe consequences for the statistical results.

Our message is therefore clear. When analyzing microeconometric panel data, we strongly recommend not to use the CrossReg approach but rather to rely on a technique which explicitly accounts for likely cross-sectional dependence in the data. In this paper, we discuss two such methodologies: The traditional CalTime approach and the GCT-regression model. 


\section{References}

Anderson, Anders, 2004, All guts, no glory: Trading and diversification among online investors, European Financial Management, forthcoming.

Arellano, Manuel, 1987, Computing robust standard errors for within-groups estimators, $O x$ ford Bulletin of Economics and Statistics 49, 431-434.

Bailey, Warren, Alok Kumar, and David Ng, 2005, Home bias of u.s. individual investors: Causes and consequences, Working Paper, Cornell University.

Barber, Brad M., and Terrance Odean, 2000, Trading is hazardous to your wealth: The common stock investment performance of individual investors, Journal of Finance 55, 773-806.

— , 2001, Boys will be boys: Gender, overconfidence, and common stock investment, Quarterly Journal of Economics 116, 261-292.

, 2002, Online investors: Do the slow die first?, Review of Financial Studies 15, 455487.

Brav, Alon, and Paul Gompers, 1997, Myth or reality? the long-run underperformance of initial public offerings: Evidence from venture and non-venture-backed companies, Journal of Finance 52, 1791-1821.

Carhart, Mark M., 1997, On persistence in mutual fund performance, Journal of Finance 52, 57-82.

Cocca, Theodoro D., and Rudolf Volkart, 2006, Equity ownership in switzerland, Swiss Banking Institute, University of Zurich.

Dahlquist, Magnus, Stefan Engström, and Paul Söderlind, 2000, Performance and characteristics of swedish mutual funds, Journal of Financial and Quantitative Analysis 35, 409-423.

Deutsches Aktieninstitut, 2006, Factbook (Frankfurt am Main).

Dorn, Daniel, and Gur Huberman, 2005, Talk and action: What individual investors say and what they do, Review of Finance 9, 437-481.

, and Paul Sengmueller, 2005, Correlated trading and returns, Working Paper, Columbia University.

Driscoll, John C., and Aart C. Kraay, 1998, Consistent covariance matrix estimation with spatially dependent panel data, Review of Economics and Statistics 80, 549-560.

Eckbo, B. Espen, and David C. Smith, 1998, The conditional performance of insider trades, Journal of Finance 53, 467-498.

Fama, Eugene F., 1998, Market efficiency, long-term returns and behavioral finance, Journal of Financial Economics 49, 283-307. 
, and Kenneth R. French, 1993, Common risk factors in the returns of bonds and stocks, Journal of Financial Economics 33, 3-56.

Feng, Lei, and Mark S. Seasholes, 2004a, Correlated trading and location, Journal of Finance 59, 2117-2144.

— , 2004b, Location effects and portfolio tilting, Working Paper, University of Berkeley.

— 2006 , Individual investors and gender similarities in an emerging stock market, Pacific Basin Finance Journal, forthcoming.

Ferson, Wayne E., and Rudi W. Schadt, 1996, Measuring fund strategy and performance in changing economic conditions, Journal of Finance 51, 425-461.

French, Kenneth R., and James M. Poterba, 1991, Investor diversification and international equity markets, American Economic Review 81, 222-226.

Goetzmann, William, Massimo Massa, and Andrei Simonov, 2004, Portfolio diversification, proximity investment and city agglomeration, Working Paper, Centre for Economic Policy Research (CEPR), No. 4786.

Gompers, Paul A., and Josh Lerner, 2003, The really long-run performance of initial public offerings: The pre-nasdaq evidence, Journal of Finance 58, 1355-1392.

Hertzel, Michael, Michael Lemmon, James S Linck, and Lynn Rees, 2002, Long-run performance following private placements of equity, Journal of Finance 57, 2595-2617.

Hoechle, Daniel, 2006, Robust standard errors for panel regressions with cross-sectional dependence, Working Paper.

Ince, Ozgur, and R. Burt Porter, 2004, Individual equity return data from thomson datastream: Handle with care!, Working Paper, University of Florida.

Ivkovic, Zoran, James Poterba, and Scott Weisbenner, 2005, Tax-motivated trading by individual investors, The American Economic Review 95, 1605-1630.

Ivkovic, Zoran, Clemens Sialm, and Scott Weisbenner, 2006, Portfolio concentration and the performance of individual investors, Journal of Financial and Quantitative Analysis, forthcoming.

Ivkovic, Zoran, and Scott Weisbenner, 2005, Local does as local is: Information content of the geography of individual investors' common stock investments, Journal of Finance 60, 267-306.

Jaffe, Jeffrey F., 1974, Special information and insider trading, The Journal of Business 47, $410-428$.

Jeng, Leslie A., Andrew Metrick, and Richard Zeckhauser, 2003, Estimating the returns to insider trading: A performance-evaluation perspective, The Review of Economics and Statistics pp. $453-471$. 
Jensen, Michael C., 1968, The performance of mutual funds in the period 1945-1964, Journal of Finance 23, 389-416.

Keim, Donald, and Ananth Madhavan, 1998, The cost of institutional equity trades, Financial Analysts Journal 54, 50-69.

Kho, Bong-Chan, Rene M. Stulz, and Francis E. Warnock, 2006, Financial globalization, governance, and the evolution of the home bias, NBER Working Paper, No. 12389.

Korniotis, George, and Alok Kumar, 2006, Does investment skill decline due to cognitive aging or improve with experience?, Working Paper.

Kumar, Alok, and Charles M.C. Lee, 2006, Retail investor sentiment and return comovements, Journal of Finance 61, 2451-2486.

Loughran, Tim, and Jay R. Ritter, 2000, Uniformly least powerful tests of market efficiency, Journal of Financial Economics 55, 361-389.

Lyon, John D., Brad M. Barber, and Chih-Ling Tsai, 1999, Improved methods for tests of long-run abnormal stock returns, Journal of Finance 54, 165-201.

Mandelker, Gershon, 1974, Risk and return: The case of merging firms, Journal of Financial Economics 1, 303-335.

Massa, Massimo, and Andrei Simonov, 2006, Hedging, familiarity and portfolio choice, Review of Financial Studies 19, 633-685.

Mitchell, Mark L., and Erik Stafford, 2000, Managerial decisions and long-term stock price performance, Journal of Business 73, 287-329.

Newey, Whitney K., and Kenneth D. West, 1987, A simple, positive semi-definite, heteroskedasticity and autocorrelation consistent covariance matrix, Econometrica 55, 703708 .

Odean, Terrance, 1999, Do investors trade too much?, American Economic Review 89, 12791298.

Poterba, James M., 2001, Demographic structure and asset returns, The Review of Economics and Statistics 83, 565-584.

, 2004, The impact of population aging on financial markets, NBER Working Paper No. 10851 .

Seasholes, Mark S., and Ning Zhu, 2005, Is there information in the local portfolio choices of individuals?, Working Paper, University of California, Berkeley.

— 2006, Individual investors and information diffusion, Working Paper, University of California, Berkeley. 
Shorrocks, Anthony F., 1975, The age-wealth relationship: A cross-section and cohort analysis, The Review of Economics and Statistics 57, 155-163.

Sydsaeter, Knut, Arne Strom, and Peter Berck, 2000, Economists' Mathematical Manual (Springer: Berlin and Heidelberg) 3rd edn.

White, Halbert, 1980, A heteroskedasticity-consistent covariance matrix estimator and a direct test for heteroskedasticity, Econometrica 48, 817-838. 


\section{Appendix A Proof of Propositions 1 through 3}

\section{A.1 Proof of Proposition 1}

\section{A.1.1 Part 1}

The dependent variable in regression model (3) is $\Delta y_{t}=R_{w t}-R_{m t}=y_{w t}-y_{m t}$ which by using matrix algebra can be computed as

$$
\begin{aligned}
\Delta y_{t} & =\mathbf{y}_{t}^{\prime} \mathbf{Z}\left(\mathbf{Z}^{\prime} \mathbf{Z}\right)^{-1} \mathbf{e}_{2}=\left[\begin{array}{ll}
y_{m t} & \Delta y_{t}
\end{array}\right] \mathbf{e}_{2} \\
\text { with } \mathbf{Z}^{\prime} & =\left[\begin{array}{ccccc}
1 & 1 & 1 & \cdots & 1 \\
z_{1}^{(w)} & z_{2}^{(w)} & z_{3}^{(w)} & \cdots & z_{N}^{(w)}
\end{array}\right]=\left[\begin{array}{c}
\iota_{N}^{\prime} \\
\mathbf{z}_{w}^{\prime}
\end{array}\right], \\
\mathbf{y}_{t}^{\prime} & =\left[\begin{array}{lll}
y_{1 t} & \cdots & y_{N t}
\end{array}\right], \text { and } \\
\mathbf{e}_{2}^{\prime} & =\left[\begin{array}{ll}
0 & 1
\end{array}\right]
\end{aligned}
$$

$\mathbf{z}_{w}^{\prime}$ is a dummy variable which is 1 if investor $h$ belongs to group $j=w$ and zero otherwise. The second step of the CalTime procedure then estimates the $k$-factor regression model in (3) by OLS. This yields the following coefficient estimates

$$
\begin{aligned}
& \hat{\beta}_{\Delta}=\left(\mathbf{X}^{\prime} \mathbf{X}\right)^{-1} \mathbf{X}^{\prime}\left[\begin{array}{c}
\Delta y_{1} \\
\vdots \\
\Delta y_{T}
\end{array}\right]=\left(\mathbf{X}^{\prime} \mathbf{X}\right)^{-1} \mathbf{X}^{\prime}\left[\begin{array}{c}
\mathbf{y}_{1}^{\prime} \mathbf{Z}\left(\mathbf{Z}^{\prime} \mathbf{Z}\right)^{-1} \mathbf{e}_{2} \\
\vdots \\
\mathbf{y}_{T}^{\prime} \mathbf{Z}\left(\mathbf{Z}^{\prime} \mathbf{Z}\right)^{-1} \mathbf{e}_{2}
\end{array}\right] \\
& =\left(\mathbf{X}^{\prime} \mathbf{X}\right)^{-1} \mathbf{X}^{\prime}\left[\begin{array}{c}
\mathbf{y}_{1}^{\prime} \\
\vdots \\
\mathbf{y}_{T}^{\prime}
\end{array}\right] \mathbf{Z}\left(\mathbf{Z}^{\prime} \mathbf{Z}\right)^{-1} \mathbf{e}_{2} \\
& =\left(\mathbf{X}^{\prime} \mathbf{X}\right)^{-1} \mathbf{X}^{\prime}\left[\begin{array}{llll}
\gamma_{1} & \gamma_{2} & \cdots & \gamma_{N}
\end{array}\right] \mathbf{Z}\left(\mathbf{Z}^{\prime} \mathbf{Z}\right)^{-1} \mathbf{e}_{2} \\
& =\left(\mathbf{X}^{\prime} \mathbf{X}\right)^{-1} \mathbf{X}^{\prime} \mathbf{Y} \mathbf{Z}\left(\mathbf{Z}^{\prime} \mathbf{Z}\right)^{-1} \mathbf{e}_{2}
\end{aligned}
$$


where $\gamma_{h}=\left[\begin{array}{llll}y_{h 1} & y_{h 2} & \cdots & y_{h T}\end{array}\right]^{\prime}$. Now, we turn to the panel regression model in (4) which we write in matrix notation as follows:

$$
\left[\begin{array}{c}
y_{11} \\
y_{12} \\
\vdots \\
y_{1 T} \\
y_{21} \\
\vdots \\
y_{N T}
\end{array}\right]=\left[\begin{array}{cccc}
1 & x_{11} & \cdots & x_{k 1} z_{1}^{(w)} \\
1 & x_{12} & \cdots & x_{k 2} z_{1}^{(w)} \\
\vdots & \vdots & \ddots & \vdots \\
1 & x_{1 T} & \cdots & x_{k T} z_{1}^{(w)} \\
1 & x_{11} & \cdots & x_{k 1} z_{2}^{(w)} \\
\vdots & \vdots & \ddots & \vdots \\
1 & x_{1 T} & \cdots & x_{k T} z_{N}^{(w)}
\end{array}\right]\left[\begin{array}{c}
d_{0,0} \\
d_{0,1} \\
\vdots \\
d_{0, k} \\
d_{1,0} \\
\vdots \\
d_{1, k}
\end{array}\right]+\left[\begin{array}{c}
v_{11} \\
v_{12} \\
\vdots \\
v_{1 T} \\
v_{21} \\
\vdots \\
v_{N T}
\end{array}\right]
$$

or more briefly:

$$
\operatorname{vec}(\mathbf{Y})=\left[\begin{array}{c}
\gamma_{1} \\
\gamma_{2} \\
\vdots \\
\gamma_{N}
\end{array}\right]=(\mathbf{Z} \otimes \mathbf{X}) \mathbf{d}+\mathbf{v}
$$

Here, $(\mathbf{Z} \otimes \mathbf{X})$ denotes the Kronecker product of matrix $\mathbf{Z}$ with matrix $\mathbf{X}$. Estimating (A3) with OLS and applying the calculus rules for the Kronecker product yields the following coefficient estimates for $\mathbf{d}$ :

$$
\begin{aligned}
\hat{\mathbf{d}} & =\left((\mathbf{Z} \otimes \mathbf{X})^{\prime}(\mathbf{Z} \otimes \mathbf{X})\right)^{-1}(\mathbf{Z} \otimes \mathbf{X})^{\prime} \operatorname{vec}(\mathbf{Y}) \\
& =\left(\left(\mathbf{Z}^{\prime} \otimes \mathbf{X}^{\prime}\right)(\mathbf{Z} \otimes \mathbf{X})\right)^{-1}(\mathbf{Z} \otimes \mathbf{X})^{\prime} \operatorname{vec}(\mathbf{Y}) \\
& =\left(\mathbf{Z}^{\prime} \mathbf{Z} \otimes \mathbf{X}^{\prime} \mathbf{X}\right)^{-1}\left(\mathbf{Z}^{\prime} \otimes \mathbf{X}^{\prime}\right) \operatorname{vec}(\mathbf{Y}) \\
& =\left(\left(\mathbf{Z}^{\prime} \mathbf{Z}\right)^{-1} \otimes\left(\mathbf{X}^{\prime} \mathbf{X}\right)^{-1}\right)\left(\mathbf{Z}^{\prime} \otimes \mathbf{X}^{\prime}\right) \operatorname{vec}(\mathbf{Y}) \\
& =\left(\left(\mathbf{Z}^{\prime} \mathbf{Z}\right)^{-1} \mathbf{Z}^{\prime} \otimes\left(\mathbf{X}^{\prime} \mathbf{X}\right)^{-1} \mathbf{X}^{\prime}\right) \operatorname{vec}(\mathbf{Y})
\end{aligned}
$$

Next, we use this well-known Lemma from linear algebra (e.g. see Sydsaeter, Strom, and Berck (2000, p. 146)):

Lemma 2 For any three matrices $\mathbf{A} \in \mathbb{R}^{r, r}, \mathbf{B} \in \mathbb{R}^{r, s}$, and $\mathbf{C} \in \mathbb{R}^{s, s}$ it holds true that 
$\operatorname{vec}(\mathbf{A B C})=\left(\mathbf{C}^{\prime} \otimes \mathbf{A}\right) \operatorname{vec}(\mathbf{B})$

and rewrite expression (A-4) as

$$
\begin{aligned}
\tilde{\mathbf{d}}=\left[\begin{array}{cc}
\hat{d}_{0,0} & \hat{d}_{1,0} \\
\vdots & \vdots \\
\hat{d}_{0, k} & \hat{d}_{1, k}
\end{array}\right] & =\left(\mathbf{X}^{\prime} \mathbf{X}\right)^{-1} \mathbf{X}^{\prime}\left[\begin{array}{llll}
\gamma_{1} & \gamma_{2} & \cdots & \gamma_{N}
\end{array}\right]\left(\left(\mathbf{Z}^{\prime} \mathbf{Z}\right)^{-1} \mathbf{Z}^{\prime}\right)^{\prime} \\
& =\left(\mathbf{X}^{\prime} \mathbf{X}\right)^{-1} \mathbf{X}^{\prime} \mathbf{Y} \mathbf{Z}\left(\mathbf{Z}^{\prime} \mathbf{Z}\right)^{-1}
\end{aligned}
$$

Finally, note that the first part of Proposition 1 states that the coefficient estimates from regression model (3) coincide with the coefficient estimates for $d_{1, s}$ in (4). Therefore, we are only interested in the second column of matrix $\tilde{\mathbf{d}}$ in (A-5). To obtain the second column of matrix $\tilde{\mathbf{d}}$ we have to post-multiply (A-5) with $\mathbf{e}_{2}=\left[\begin{array}{ll}0 & 1\end{array}\right]^{\prime}$. The resulting expression is identical to (A-2) which completes the proof.

\section{A.1.2 Part 2}

In order to obtain $y_{m t}$, we have to post multiply (A-1) by $\mathbf{e}_{1}=\left[\begin{array}{ll}1 & 0\end{array}\right]^{\prime}$ rather than by $\mathbf{e}_{2}=\left[\begin{array}{ll}0 & 1\end{array}\right]^{\prime}$. Hence, estimating the the $k$-factor regression model in (2) produces the following coefficient estimates for $\beta_{m}$ :

$$
\hat{\beta}_{m}=\left(\mathbf{X}^{\prime} \mathbf{X}\right)^{-1} \mathbf{X}^{\prime} \mathbf{Y} \mathbf{Z}\left(\mathbf{Z}^{\prime} \mathbf{Z}\right)^{-1} \mathbf{e}_{1}
$$

Next, we consider that the second part of Proposition 1 states that the coefficient estimates from regression model (2) coincide with the coefficient estimates for $d_{0, s}$ in (4). Therefore, we only need the first column of matrix $\tilde{\mathbf{d}}$ in (A-5). To obtain the respective column, we post-multiply (A-5) with $\mathbf{e}_{1}$. The resulting expression is identical to (A-6) which completes the proof. 


\section{A.2 Proof of Proposition 2}

\section{A.2.1 Part 1}

The formula for computing the Newey and West (1987) covariance matrix with lag length $H$ for the regression model in equation (3) is

$$
\begin{aligned}
& V^{*}\left\{\hat{\beta}_{\Delta}\right\}=\left(\mathbf{X}^{\prime} \mathbf{X}\right)^{-1} \hat{S}_{T}\left(\mathbf{X}^{\prime} \mathbf{X}\right)^{-1} \\
& \text { with } \hat{S}_{T}=\sum_{t=1}^{T} \hat{\varepsilon}_{\Delta t}^{2} \mathbf{x}_{t}^{\prime} \mathbf{x}_{t}+\sum_{j=1}^{H} w_{j, H} \sum_{q=j+1}^{T}\left(\hat{\varepsilon}_{\Delta q} \hat{\varepsilon}_{\Delta q-j}\left(\mathbf{x}_{q}^{\prime} \mathbf{x}_{q-j}+\mathbf{x}_{q-j}^{\prime} \mathbf{x}_{q}\right)\right)
\end{aligned}
$$

where $\mathbf{x}_{t}=\left[\begin{array}{llll}1 & x_{1 t} & \ldots & x_{k t}\end{array}\right]$ is a $(k+1)$-dimensional row vector. The modified Bartlett weights $w_{j, H}=1-j /(H+1)$ ensure positive semi-definiteness of $\hat{S}_{T}$ and smooth the sample autocovariance function such that higher order lags receive less weight. Using Corollary 1 we can rewrite residual $\hat{\varepsilon}_{\Delta q}$ in $(\mathrm{A}-7)$ as

$$
\hat{\varepsilon}_{\Delta q}=N_{w}^{-1} \sum_{h=1}^{N_{w}} \hat{\varepsilon}_{h w q}-N_{m}^{-1} \sum_{h=1}^{N_{m}} \hat{\varepsilon}_{h m q} \equiv N_{w}^{-1} W_{q}-N_{m}^{-1} M_{q}
$$

$\hat{\varepsilon}_{h j q}$ denotes the period $q$ residual of investor $h$ from group $j$ where the coefficient estimates $\hat{\beta}_{j s}$ $(s=0,1, \ldots, k)$ are obtained from estimating regression (2) for group $j . W_{q}$ and $M_{q}$ refer to the period $q$ sum of the $\hat{\varepsilon}_{h j t}$ for group $j=w$ and $j=m$, respectively. Replacing $\hat{\varepsilon}_{\Delta q}$ in (A-7) by the corresponding term from (A-8) yields

$$
\begin{aligned}
\hat{S}_{T} & =\sum_{t=1}^{T}\left(N_{w}^{-1} W_{t}-N_{m}^{-1} M_{t}\right)^{2} \mathbf{x}_{t}^{\prime} \mathbf{x}_{t} \\
& +\sum_{j=1}^{H} w_{j, H} \sum_{q=j+1}^{T}\left(\left(N_{w}^{-1} W_{q}-N_{m}^{-1} M_{q}\right)\left(N_{w}^{-1} W_{q-j}-N_{m}^{-1} M_{q-j}\right)\left(\mathbf{x}_{q}^{\prime} \mathbf{x}_{q-j}+\mathbf{x}_{q-j}^{\prime} \mathbf{x}_{q}\right)\right)
\end{aligned}
$$


Next, we turn to the Driscoll and Kraay (1998) covariance matrix estimator for the pooled OLS regression model in (4). For $H$ lags, it has the following structure:

$$
\begin{aligned}
\tilde{V}\{\hat{\mathbf{d}}\} & =\left((\mathbf{Z} \otimes \mathbf{X})^{\prime}(\mathbf{Z} \otimes \mathbf{X})\right)^{-1} \tilde{S}_{T}\left((\mathbf{Z} \otimes \mathbf{X})^{\prime}(\mathbf{Z} \otimes \mathbf{X})\right)^{-1} \\
\text { with } \quad \tilde{S}_{T} & =\hat{\Omega}_{0}+\sum_{j=1}^{H} w_{j, H}\left(\hat{\Omega}_{j}+\hat{\Omega}_{j}^{\prime}\right), \\
\hat{\Omega}_{j} & =\sum_{q=j+1}^{T} \mathbf{h}_{q}(\hat{\mathbf{d}}) \mathbf{h}_{q-j}^{\prime}(\hat{\mathbf{d}}), \text { and } \mathbf{h}_{q}(\hat{\mathbf{d}})=\left(\mathbf{Z} \otimes \mathbf{x}_{q}\right)^{\prime} \mathbf{v}_{q}
\end{aligned}
$$

Matrix $(\mathbf{Z} \otimes \mathbf{X})$ has been defined in expression (A-3) above. By using the period $q$ row vector $\mathbf{x}_{q}=\left[\begin{array}{llll}1 & x_{1 q} & \ldots & x_{k q}\end{array}\right]$ which contains a constant and all the market level variables, we can rewrite the $(2 k+2)$ moment conditions $\mathbf{h}_{q}(\hat{\mathbf{d}})$ as

$$
\mathbf{h}_{q}(\hat{\mathbf{d}})=\left(\mathbf{Z} \otimes \mathbf{x}_{q}\right)^{\prime} \mathbf{v}_{q}=\left[\begin{array}{c}
\sum_{h=1}^{N} v_{h q} \\
x_{1 q} \sum_{h=1}^{N} v_{h q} \\
\vdots \\
x_{k q} \sum_{h=1}^{N} v_{h q} \\
x_{1 q} \sum_{h=1}^{N_{w}} \varepsilon_{h w q} \\
\vdots \\
x_{k q} \sum_{h=1}^{N_{w}} \varepsilon_{h w q}
\end{array}\right]=\left[\begin{array}{cc}
\mathbf{x}_{q}^{\prime} & \mathbf{x}_{q}^{\prime} \\
\mathbf{x}_{q}^{\prime} & \mathbf{0}
\end{array}\right]\left[\begin{array}{c}
W_{q} \\
M_{q}
\end{array}\right]
$$


Next, we define $T_{q}=W_{q}+M_{q}$ and consider the $((2 k+2) \times(2 k+2))$ matrix $\hat{\Omega}_{j}$ :

$$
\begin{aligned}
\hat{\mathbf{\Omega}}_{j} & =\sum_{q=j+1}^{T} \mathbf{h}_{q}(\hat{\mathbf{d}}) \mathbf{h}_{q-j}^{\prime}(\hat{\mathbf{d}}) \\
& =\sum_{q=j+1}^{T}\left(\left[\begin{array}{cc}
\mathbf{x}_{q}^{\prime} & \mathbf{x}_{q}^{\prime} \\
\mathbf{x}_{q}^{\prime} & \mathbf{0}
\end{array}\right]\left[\begin{array}{c}
W_{q} \\
M_{q}
\end{array}\right]\left[\begin{array}{ll}
W_{q-j} & M_{q-j}
\end{array}\right]\left[\begin{array}{cc}
\mathbf{x}_{q-j} & \mathbf{x}_{q-j} \\
\mathbf{x}_{q-j} & \mathbf{0}
\end{array}\right]\right) \\
& =\sum_{q=j+1}^{T}\left[\begin{array}{cc}
T_{q} T_{q-j} \mathbf{x}_{q}^{\prime} \mathbf{x}_{q-j} & T_{q} W_{q-j} \mathbf{x}_{q}^{\prime} \mathbf{x}_{q-j} \\
W_{q} T_{q-j} \mathbf{x}_{q}^{\prime} \mathbf{x}_{q-j} & W_{q} W_{q-j} \mathbf{x}_{q}^{\prime} \mathbf{x}_{q-j}
\end{array}\right]
\end{aligned}
$$

As a result, matrix $\tilde{S}_{T}$ in (A-10) can be written in block form as follows:

$$
\tilde{S}_{T}=\left[\begin{array}{ll}
\Lambda_{1} & \Lambda_{2} \\
\Lambda_{3} & \Lambda_{4}
\end{array}\right]
$$

where

$$
\begin{gathered}
\Lambda_{1}=\sum_{t=1}^{T} T_{t}^{2} \mathbf{x}_{t}^{\prime} \mathbf{x}_{t}+\sum_{j=1}^{H} w_{j, H} \sum_{q=j+1}^{T} T_{q} T_{q-j}\left(\mathbf{x}_{q}^{\prime} \mathbf{x}_{q-j}+\mathbf{x}_{q-j}^{\prime} \mathbf{x}_{q}\right) \\
\Lambda_{2}=\sum_{t=1}^{T} T_{t} W_{t} \mathbf{x}_{t}^{\prime} \mathbf{x}_{t}+\sum_{j=1}^{H} w_{j, H} \sum_{q=j+1}^{T}\left(T_{q} W_{q-j} \mathbf{x}_{q}^{\prime} \mathbf{x}_{q-j}+T_{q-j} W_{q} \mathbf{x}_{q-j}^{\prime} \mathbf{x}_{q}\right) \\
\Lambda_{3}=\sum_{t=1}^{T} T_{t} W_{t} \mathbf{x}_{t}^{\prime} \mathbf{x}_{t}+\sum_{j=1}^{H} w_{j, H} \sum_{q=j+1}^{T}\left(W_{q} T_{q-j} \mathbf{x}_{q}^{\prime} \mathbf{x}_{q-j}+W_{q-j} T_{q} \mathbf{x}_{q-j}^{\prime} \mathbf{x}_{q}\right) \\
\Lambda_{4}=\sum_{t=1}^{T} W_{t}^{2} \mathbf{x}_{t}^{\prime} \mathbf{x}_{t}+\sum_{j=1}^{H} w_{j, H} \sum_{q=j+1}^{T} W_{q} W_{q-j}\left(\mathbf{x}_{q}^{\prime} \mathbf{x}_{q-j}+\mathbf{x}_{q-j}^{\prime} \mathbf{x}_{q}\right)
\end{gathered}
$$

Next, we rewrite matrix $\left((\mathbf{Z} \otimes \mathbf{X})^{\prime}(\mathbf{Z} \otimes \mathbf{X})\right)^{-1}=\left(\mathbf{Z}^{\prime} \mathbf{Z}\right)^{-1} \otimes\left(\mathbf{X}^{\prime} \mathbf{X}\right)^{-1}$ as

$$
\begin{aligned}
\left(\mathbf{Z}^{\prime} \mathbf{Z}\right)^{-1} \otimes\left(\mathbf{X}^{\prime} \mathbf{X}\right)^{-1} & =\left[\begin{array}{cc}
N_{m}^{-1} & -N_{m}^{-1} \\
-N_{m}^{-1} & N_{w}^{-1}+N_{m}^{-1}
\end{array}\right] \otimes\left(\mathbf{X}^{\prime} \mathbf{X}\right)^{-1} \\
& =\left[\begin{array}{cc}
N_{m}^{-1}\left(\mathbf{X}^{\prime} \mathbf{X}\right)^{-1} & -N_{m}^{-1}\left(\mathbf{X}^{\prime} \mathbf{X}\right)^{-1} \\
-N_{m}^{-1}\left(\mathbf{X}^{\prime} \mathbf{X}\right)^{-1} & \left(N_{w}^{-1}+N_{m}^{-1}\right)\left(\mathbf{X}^{\prime} \mathbf{X}\right)^{-1}
\end{array}\right]
\end{aligned}
$$


and insert (A-14) into the Driscoll and Kraay (1998) estimator of (A-10) to obtain

$$
\begin{aligned}
\tilde{V}\{\hat{\mathbf{d}}\} & =\left(\left(\mathbf{Z}^{\prime} \mathbf{Z}\right)^{-1} \otimes\left(\mathbf{X}^{\prime} \mathbf{X}\right)^{-1}\right) \tilde{S}_{T}\left(\left(\mathbf{Z}^{\prime} \mathbf{Z}\right)^{-1} \otimes\left(\mathbf{X}^{\prime} \mathbf{X}\right)^{-1}\right) \\
& =\left[\begin{array}{cc}
\Theta_{1} & \Theta_{2} \\
\Theta_{3} & \Theta_{4}
\end{array}\right]
\end{aligned}
$$

where

$$
\begin{aligned}
& \Theta_{1}=N_{m}^{-2}\left(\mathbf{X}^{\prime} \mathbf{X}\right)^{-1}\left(\Lambda_{1}-\Lambda_{2}-\Lambda_{3}+\Lambda_{4}\right)\left(\mathbf{X}^{\prime} \mathbf{X}\right)^{-1} \\
& \Theta_{2}=N_{m}^{-1} N_{w}^{-1}\left(\mathbf{X}^{\prime} \mathbf{X}\right)^{-1}\left(\Lambda_{2}-\Lambda_{4}\right)\left(\mathbf{X}^{\prime} \mathbf{X}\right)^{-1}-\Theta_{1} \\
& \Theta_{3}=N_{m}^{-1} N_{w}^{-1}\left(\mathbf{X}^{\prime} \mathbf{X}\right)^{-1}\left(\Lambda_{3}-\Lambda_{4}\right)\left(\mathbf{X}^{\prime} \mathbf{X}\right)^{-1}-\Theta_{1} \\
& \Theta_{4}=N_{w}^{-2}\left(\mathbf{X}^{\prime} \mathbf{X}\right)^{-1} \Lambda_{4}\left(\mathbf{X}^{\prime} \mathbf{X}\right)^{-1}-\Theta_{1}-\Theta_{2}-\Theta_{3}
\end{aligned}
$$

To complete the proof of the first part of Proposition 2, we therefore have to show that $\Theta_{4}$ in the Driscoll-Kraay covariance matrix $\tilde{V}\{\hat{\mathrm{d}}\}$ from (A-15) coincides with the Newey-West estimator $V^{*}\left\{\hat{\beta}_{\Delta}\right\}$ in (A-7). Thus, we simplify the $\Lambda$ terms in (A-15) as follows

$$
\begin{gathered}
\Lambda_{1}-\Lambda_{2}-\Lambda_{3}+\Lambda_{4}=\sum_{t=1}^{T} M_{t}^{2} \mathbf{x}_{t}^{\prime} \mathbf{x}_{t}+\sum_{j=1}^{H} w_{j, H} \sum_{q=j+1}^{T} M_{q} M_{q-j}\left(\mathbf{x}_{q}^{\prime} \mathbf{x}_{q-j}+\mathbf{x}_{q-j}^{\prime} \mathbf{x}_{q}\right) \\
\Lambda_{2}-\Lambda_{4}=\sum_{t=1}^{T}\left(M_{t} W_{t}\right) \mathbf{x}_{t}^{\prime} \mathbf{x}_{t}+\sum_{j=1}^{H} w_{j, H} \sum_{q=j+1}^{T}\left(\left(M_{q} W_{q-j}\right) \mathbf{x}_{q}^{\prime} \mathbf{x}_{q-j}+\left(M_{q-j} W_{q}\right) \mathbf{x}_{q-j}^{\prime} \mathbf{x}_{q}\right) \\
\Lambda_{3}-\Lambda_{4}=\sum_{t=1}^{T}\left(W_{t} M_{t}\right) \mathbf{x}_{t}^{\prime} \mathbf{x}_{t}+\sum_{j=1}^{H} w_{j, H} \sum_{q=j+1}^{T}\left(\left(W_{q} M_{q-j}\right) \mathbf{x}_{q}^{\prime} \mathbf{x}_{q-j}+\left(W_{q-j} M_{q}\right) \mathbf{x}_{q-j}^{\prime} \mathbf{x}_{q}\right)
\end{gathered}
$$

and insert the resulting expressions into $\Theta_{4}$ from (A-15) to finally obtain

$$
\Theta_{4}=\left(\mathbf{X}^{\prime} \mathbf{X}\right)^{-1} \tilde{Q}_{T}\left(\mathbf{X}^{\prime} \mathbf{X}\right)^{-1}
$$


with

$$
\begin{aligned}
\tilde{Q}_{T} & =\sum_{t=1}^{T}\left(N_{w}^{-1} W_{t}-N_{m}^{-1} M_{t}\right)^{2} \mathbf{x}_{t}^{\prime} \mathbf{x}_{t} \\
& +\sum_{j=1}^{H} w_{j, H} \sum_{q=j+1}^{T}\left(\left(N_{w}^{-1} W_{q}-N_{m}^{-1} M_{q}\right)\left(N_{w}^{-1} W_{q-j}-N_{m}^{-1} M_{q-j}\right)\right)\left(\mathbf{x}_{q}^{\prime} \mathbf{x}_{q-j}+\mathbf{x}_{q-j}^{\prime} \mathbf{x}_{q}\right)
\end{aligned}
$$

Since $\tilde{Q}_{T}$ in (A-16) and $\hat{S}_{T}$ in (A-9) are identical, this completes the proof.

\section{A.2.2 Part 2}

To prove the second part of Proposition 2, we have to show that $\Theta_{1}$ from (A-15) is identical to the Newey-West covariance matrix

$$
\begin{aligned}
V^{*}\left\{\hat{\beta}_{\Delta}\right\} & =\left(\mathbf{X}^{\prime} \mathbf{X}\right)^{-1} \hat{S}_{T}^{m}\left(\mathbf{X}^{\prime} \mathbf{X}\right)^{-1} \\
\text { with } \hat{S}_{T}^{m} & =\sum_{t=1}^{T} N_{m}^{-2} M_{t}^{2} \mathbf{x}_{t}^{\prime} \mathbf{x}_{t} \\
& +\sum_{j=1}^{H} w_{j, H} \sum_{q=j+1}^{T}\left(N_{m}^{-2} M_{q} M_{q-j}\left(\mathbf{x}_{q}^{\prime} \mathbf{x}_{q-j}+\mathbf{x}_{q-j}^{\prime} \mathbf{x}_{q}\right)\right)
\end{aligned}
$$

for the coefficient estimates of the men's portfolio in regression (2). By replacing $\Lambda_{1}-\Lambda_{2}-$ $\Lambda_{3}+\Lambda_{4}$ with the corresponding term derived above, we obtain the following expression for $\Theta_{1}$ :

$$
\Theta_{1}=\left(\mathbf{X}^{\prime} \mathbf{X}\right)^{-1} \tilde{Q}_{T}^{m}\left(\mathbf{X}^{\prime} \mathbf{X}\right)^{-1}
$$

$$
\begin{aligned}
\text { with } \tilde{Q}_{T}^{m} & =\sum_{t=1}^{T} N_{m}^{-2} M_{t}^{2} \mathbf{x}_{t}^{\prime} \mathbf{x}_{t} \\
& +\sum_{j=1}^{H-1} w_{j, H} \sum_{q=j+1}^{T} N_{m}^{-2} M_{q} M_{q-j}\left(\mathbf{x}_{q}^{\prime} \mathbf{x}_{q-j}+\mathbf{x}_{q-j}^{\prime} \mathbf{x}_{q}\right)
\end{aligned}
$$

Since $\tilde{Q}_{T}^{m}$ in (A-18) and $\hat{S}_{T}^{m}$ in (A-17) are identical, this completes the proof. 


\section{A.3 Proof of Proposition 3}

Let $s$ be fixed to $s=\tilde{s} \in\{0, \ldots, k\}$. Then it follows from (A-5) that for the generalized CalTime regression model in $(G C T)$ vector $\hat{\mathbf{d}}_{\tilde{s}}^{\prime}=\left[\begin{array}{lll}\hat{d}_{0, \tilde{s}} & \cdots & \hat{d}_{m, \tilde{s}}\end{array}\right]$ which contains the coefficient estimates for $d_{q, \tilde{s}}$ is given by

$$
\begin{gathered}
\hat{\mathbf{d}}_{\tilde{s}}=\left[\begin{array}{c}
\hat{d}_{0, \tilde{s}} \\
\vdots \\
\hat{d}_{m, \tilde{s}}
\end{array}\right]=\left[\begin{array}{ccc}
\hat{d}_{0,0} & \cdots & \hat{d}_{m, 0} \\
\vdots & \ddots & \vdots \\
\hat{d}_{0, k} & \cdots & \hat{d}_{m, k}
\end{array}\right]^{\prime}\left[\begin{array}{c}
0 \\
\vdots \\
1 \\
0
\end{array}\right] \\
=\left(\mathbf{Z}^{\prime} \mathbf{Z}\right)^{-1} \mathbf{Z}^{\prime} \mathbf{Y}^{\prime} \mathbf{X}\left(\mathbf{X}^{\prime} \mathbf{X}\right)^{-1} \mathbf{e}_{(\tilde{s}+1)}
\end{gathered}
$$

Here, $\mathbf{e}_{(\tilde{s}+1)}$ is a $(m+1) \times 1$ vector whose $(\tilde{s}+1)$-th element is equal to one and all other elements are zero.

Next, we turn to the CrossReg methodology. Estimating the first step regression for investor $h$ by OLS yields the following coefficient estimates:

$$
\hat{\beta}_{h}=\left[\begin{array}{c}
\hat{\beta}_{0, h} \\
\hat{\beta}_{1, h} \\
\vdots \\
\hat{\beta}_{k, h}
\end{array}\right]=\left(\mathbf{X}^{\prime} \mathbf{X}\right)^{-1} \mathbf{X}^{\prime} \gamma_{h}
$$

where $\gamma_{h}^{\prime}=\left[\begin{array}{llll}y_{h 1} & y_{h 2} & \cdots & y_{h T}\end{array}\right]$. Stacking the transpose of all $N$ OLS coefficient vectors from (A-20) produces

$$
\left[\begin{array}{cccc}
\hat{\beta}_{0,1} & \hat{\beta}_{1,1} & \cdots & \hat{\beta}_{k, 1} \\
\hat{\beta}_{0,2} & \hat{\beta}_{1,2} & \cdots & \hat{\beta}_{k, 2} \\
\vdots & \vdots & \ddots & \vdots \\
\hat{\beta}_{0, N} & \hat{\beta}_{1, N} & \cdots & \hat{\beta}_{k, N}
\end{array}\right]=\left[\begin{array}{c}
\gamma_{1}^{\prime} \\
\gamma_{2}^{\prime} \\
\vdots \\
\gamma_{N}^{\prime}
\end{array}\right] \mathbf{X}\left(\mathbf{X}^{\prime} \mathbf{X}\right)^{-1}=\mathbf{Y}^{\prime} \mathbf{X}\left(\mathbf{X}^{\prime} \mathbf{X}\right)^{-1}
$$


Thus, we obtain the dependent variable for the second step regression of the CrossReg approach by post-multiplying $(\mathrm{A}-21)$ with $\mathbf{e}_{(\tilde{s}+1)}$. Therefore, the OLS coefficient vector $\mathbf{c}_{\tilde{s}}$ from the second step regression $\hat{\beta}_{\tilde{s}}=\mathbf{Z}_{\tilde{s}}+\mathbf{w}_{\tilde{s}}$ of the CrossReg methodology results to be given by

$$
\hat{\mathbf{c}}_{\tilde{s}}=\left[\begin{array}{c}
\hat{c}_{0, \tilde{s}} \\
\hat{c}_{1, \tilde{s}} \\
\vdots \\
\hat{c}_{m, \tilde{s}}
\end{array}\right]=\left(\mathbf{Z}^{\prime} \mathbf{Z}\right)^{-1} \mathbf{Z}^{\prime} \mathbf{Y}^{\prime} \mathbf{X}\left(\mathbf{X}^{\prime} \mathbf{X}\right)^{-1} \mathbf{e}_{(\tilde{s}+1)} \equiv \hat{\mathbf{d}}_{\tilde{s}}
$$

Since expression (A-22) is identical to (A-19) for each $\tilde{s} \in\{0, \ldots, k\}$, this completes the proof. 


\section{Table I}

\section{Description of the investor database}

The investor database contains 41'719 investors at a renowned European wholesale bank from March 2000 to June 2005. Most accounts for whom the sex of the account holder is unknown (n.a.) in fact belong to the inheritors of an investor who died. The number of balanced bank relationships is the number of accounts that have been terminated either because an investor decided to move her money to another bank or because the bank wealth of an investor who died during the sample period was distributed amongst her inheritors. The number of new bank relationships lists the number of investors who did not maintain an account at the bank prior to March 2000 but who established an account at the bank between March 2000 and December 2003. The portfolio turnover is the average of the buy and the sell turnover. The buy (sell) turnover in month $t$ is defined as the beginning-of-month $t$ market value of the shares purchased in month $t-1$ (sold in month $t$ ) divided by the total market value of the investor's stock portfolio at the beginning of month $t$.

Panel A. Counts

\begin{tabular}{|c|c|c|c|c|c|}
\hline & & Men & Women & n.a. & All \\
\hline \multicolumn{2}{|c|}{ \# of investors in the database } & 22,402 & 18,730 & 587 & 41,719 \\
\hline \multicolumn{2}{|c|}{ \# of balanced bank relationships } & 2,822 & 2,431 & 117 & 5,370 \\
\hline \multicolumn{2}{|c|}{ \# new bank relationships } & 2,055 & 1,661 & 22 & 3,738 \\
\hline \multicolumn{2}{|c|}{ \# investors who died } & 1,608 & 1,537 & 563 & 3,708 \\
\hline \multicolumn{2}{|c|}{ \# investors with online banking transactions } & 1,443 & 438 & 11 & 1,892 \\
\hline \# of investors & below 45 & 3,679 & 2,069 & 2 & 5,750 \\
\hline grouped by age & 45 to 59 & 5,453 & 3,716 & 18 & 9,187 \\
\hline \multirow[t]{3}{*}{ (in 2005) } & 60 to 74 & 8,010 & 5,839 & 92 & 13,941 \\
\hline & 75 and above & 5,253 & 7,099 & 474 & 12,826 \\
\hline & n.a. & 7 & 7 & 1 & 15 \\
\hline
\end{tabular}

Panel B. Value, Turnover, and Trade Size of investors with position holdings in common stocks

\begin{tabular}{|c|c|c|c|c|c|}
\hline & & Men & Women & n.a. & All \\
\hline \multicolumn{2}{|c|}{ \# investors with end-of-month positions in stocks } & 7,140 & 4,200 & 165 & 11,505 \\
\hline \multirow[t]{6}{*}{ Stock portfolio } & Mean value $(\mathrm{CHF})$ & 147,620 & 118,615 & 260,612 & 138,971 \\
\hline & Median value $(\mathrm{CHF})$ & 46,596 & 43,525 & 59,508 & 45,660 \\
\hline & Mean \# of stock holdings & 4.29 & 3.48 & 3.45 & 3.98 \\
\hline & Median \# of stock holdings & 2.82 & 2.18 & 2.58 & 2.60 \\
\hline & Mean portfolio turnover p.m. (\%) & 3.40 & 2.80 & 2.07 & 3.16 \\
\hline & Median portfolio turnover p.m. (\%) & 1.33 & 0.94 & 0.96 & 1.18 \\
\hline \multirow[t]{4}{*}{ All stock trades } & \# investors with stock trades & 6,114 & 3,334 & 138 & 9,586 \\
\hline & \# transactions & 105,302 & 37,199 & 1,471 & 143,972 \\
\hline & Mean value of stock trades (CHF) & 26,727 & 26,531 & 37,813 & 26,790 \\
\hline & Med. value of stock trades (CHF) & 13,597 & 15,574 & 17,325 & 14,150 \\
\hline \multirow[t]{4}{*}{ Stock purchases } & \# investors with stock purchases & 4,803 & 2,205 & 80 & 7,088 \\
\hline & \# transactions & 54,976 & 17,552 & 570 & 73,098 \\
\hline & Mean value of stock buys (CHF) & 24,293 & 23,773 & 35,903 & 24,259 \\
\hline & Median value of stock buys (CHF) & 12,768 & 14,686 & 17,760 & 13,300 \\
\hline \multirow[t]{4}{*}{ Stock sales } & \# investors with stock sales & 5,326 & 2,944 & 132 & 8,402 \\
\hline & \# transactions & 50,326 & 19,647 & 901 & 70,874 \\
\hline & Mean value of stock sales (CHF) & 29,386 & 28,994 & 39,021 & 29,400 \\
\hline & Median value of stock sales (CHF) & 14,660 & 16,700 & 16,868 & 15,225 \\
\hline
\end{tabular}


Table II

The weight of CHF denominated stocks in the portfolios

The table measures the weight of CHF denominated stocks in the portfolios of the investors. The data set consists of 11,340 private investors with stock holdings between March 2000 and June 2005. Summary statistics are presented for the average weight of Swiss stocks in the investors' stock portfolio during the sample period. Columns labeled $p 50$ refer to the median value. * indicates statistical significance at the 1 percent level.

\begin{tabular}{|c|c|c|c|c|c|c|c|c|c|c|c|c|}
\hline & \multicolumn{3}{|c|}{ Men } & \multicolumn{3}{|c|}{ Women } & \multicolumn{3}{|c|}{ Men minus Women } & \multicolumn{3}{|c|}{ All } \\
\hline & $\mathrm{N}$ & mean & p50 & $\mathrm{N}$ & mean & p50 & $\mathrm{N}$ & mean & p50 & $\mathrm{N}$ & mean & $\mathrm{p} 50$ \\
\hline Swiss domiciled investors & 5,617 & 78.3 & 98.2 & 3,377 & 85.0 & 100.0 & 2,240 & $-6.7 *$ & $-1.8^{*}$ & 8,994 & 80.8 & 100.0 \\
\hline Non-Swiss domiciled investors & 1,523 & 46.8 & 44.3 & 823 & 56.0 & 61.1 & 700 & $-9.2 *$ & $-16.8^{*}$ & 2,346 & 50.0 & 51.2 \\
\hline Swiss citizens & 5,376 & 79.0 & 98.7 & 3,355 & 85.0 & 100.0 & 2,021 & $-6.0^{*}$ & $-1.3^{*}$ & 8,731 & 81.3 & 100.0 \\
\hline Non-Swiss citizens & 1,764 & 48.8 & 48.3 & 845 & 56.9 & 62.9 & 919 & $-8.1 *$ & $-14.6^{*}$ & 2,609 & 51.4 & 53.2 \\
\hline Swiss domicile and citizenship & 5,270 & 79.2 & 98.8 & 3,257 & 85.4 & 100.0 & 2,013 & $-6.2 *$ & $-1.2 *$ & 8,527 & 81.5 & 100.0 \\
\hline Non-Swiss domicile and citizenship & 1,417 & 44.8 & 40.4 & 725 & 53.8 & 55.9 & 692 & $-9.0^{*}$ & $-15.5^{*}$ & 2,142 & 47.8 & 46.6 \\
\hline All investors & 7,140 & 71.6 & 91.3 & 4,200 & 79.3 & 100.0 & 2,940 & $-7.8^{*}$ & $-8.7 *$ & 11,340 & 74.5 & 97.0 \\
\hline
\end{tabular}


Table III

\section{An empirical examination of Propositions 1 through 3}

This table reports the coefficient estimates and t-values (in parentheses) for three different techniques of how to evaluate the performance of private investors. All results are based on a balanced panel of 4,156 private investors with a complete history of end-of-month stock holdings at a renowned European wholesale bank from March 2000 to June 2005. Columns labeled with “CalTime” present the results for the calender time portfolio methodology. The dependent variable is the net return of a zero-investment portfolio which is long (short) in the aggregated stock portfolio of all female (male) investors. For ease of comparison with the results of the pooled OLS regression models in the columns labeled with " $P O L S$ ", the coefficient estimates and t-values of the timeseries regression of the calendar time portfolio approach are presented in the rows of the interaction terms (e.g. $S P I *$ Woman) rather than in the rows of the actual variables (e.g. SPI). The dependent variable in the pooled OLS regression models (Method= "POLS") is the individual investors' monthly net excess return. Finally, the column labeled $O L S$ contains the coefficient estimates of a cross-sectional regression. Here, the dependent variable is an investor specific 'alpha' from a Fama and French (1993) like performance measurement model which has independently been estimated for each single investor. The explanatory variables are the monthly excess return of the Swiss Performance Index (SPI), the monthly excess return of the MSCI World index (World) orthogonalized by $S P I$, the return of a zero-investment book-to-market portfolio $(H M L)$, the return of a zero-investment size portfolio $(S M B)$, a dummy variable being one if an investor is female (Woman), and all interactions between the Woman dummy and the aforementioned factor variables. The t-values of the various models are based on the following covariance matrix estimators (SE type): OLS are OLS standard errors, NW87 and NW87a refer to Newey and West (1987) standard errors with and without degree-of-freedom correction, DK98 stands for Driscoll and Kraay (1998) standard errors, $A 87$ denotes clustered or panel robust standard errors, and W80 are White (1980) standard errors. $* * * * *$, and $*$ indicate significance at the 1,5 , and 10 percent levels.

\begin{tabular}{|c|c|c|c|c|c|c|}
\hline $\begin{array}{l}\text { Method } \\
\text { SE type }\end{array}$ & $\begin{array}{l}\text { CalTime } \\
\text { OLS }\end{array}$ & $\begin{array}{l}\text { CalTime } \\
\text { NW87 }\end{array}$ & $\begin{array}{l}\text { CalTime } \\
\text { NW87a }\end{array}$ & $\begin{array}{l}\text { POLS } \\
\text { DK98 }\end{array}$ & $\begin{array}{l}\text { POLS } \\
\text { A87 }\end{array}$ & $\begin{array}{l}\text { OLS } \\
\text { W80 }\end{array}$ \\
\hline SPI*Woman & $\begin{array}{l}-0.046^{* * * *} \\
(-3.499)\end{array}$ & $\begin{array}{l}-0.046 \text { *** } \\
(-5.174)\end{array}$ & $\begin{array}{l}-0.046 * * * \\
(-5.389)\end{array}$ & $\begin{array}{l}-0.046 * * * \\
(-5.389)\end{array}$ & $\begin{array}{l}-0.046 \text { *** } \\
(-4.346)\end{array}$ & \\
\hline World*Woman & $\begin{array}{l}-0.139 * * * \\
(-9.966)\end{array}$ & $\begin{array}{l}-0.139 * * * \\
(-9.748)\end{array}$ & $\begin{array}{l}-0.139 * * * \\
(-10.152)\end{array}$ & $\begin{array}{l}-0.139 \text { *** } \\
(-10.152)\end{array}$ & $\begin{array}{l}-0.139 * * * \\
(-7.855)\end{array}$ & \\
\hline HML*Woman & $\begin{array}{l}-0.034 * * * \\
(-3.774)\end{array}$ & $\begin{array}{l}-0.034 * * * \\
(-3.534)\end{array}$ & $\begin{array}{l}-0.034 * * * \\
(-3.681)\end{array}$ & $\begin{array}{l}-0.034 * * * \\
(-3.681)\end{array}$ & $\begin{array}{l}-0.034 * * * \\
(-3.716)\end{array}$ & \\
\hline SMB*Woman & $\begin{array}{l}-0.074 * * * \\
(-5.235)\end{array}$ & $\begin{array}{l}-0.074 * * * \\
(-4.746)\end{array}$ & $\begin{array}{l}-0.074 * * * \\
(-4.943)\end{array}$ & $\begin{array}{l}-0.074 * * * \\
(-4.943)\end{array}$ & $\begin{array}{l}-0.074 * * * \\
(-5.778)\end{array}$ & \\
\hline SPI & & & & $\begin{array}{l}1.065^{* * *} \\
(44.641)\end{array}$ & $\begin{array}{c}1.065^{\text {**** }} \\
(165.306)\end{array}$ & \\
\hline World & & & & $\begin{array}{c}0.446 \text { *** } \\
(13.186)\end{array}$ & $\begin{array}{l}0.446 \text { *** } \\
(38.565)\end{array}$ & \\
\hline HML & & & & $\begin{array}{l}0.145^{* * *} \\
(6.232)\end{array}$ & $\begin{array}{l}0.145^{* * *} \\
(26.291)\end{array}$ & \\
\hline SMB & & & & $\begin{array}{r}0.040 \\
(1.447)\end{array}$ & $\begin{array}{l}0.040 * * * \\
(4.733)\end{array}$ & \\
\hline Woman & $\begin{array}{l}0.089 * * \\
(2.203)\end{array}$ & $\begin{array}{c}0.089^{*} \\
(1.941)\end{array}$ & $\begin{array}{l}0.089 * * \\
(2.021)\end{array}$ & $\begin{array}{l}0.089 * * \\
(2.021)\end{array}$ & $\begin{array}{l}0.089 * * * \\
(4.347)\end{array}$ & $\begin{array}{l}0.089 * * * \\
(4.347)\end{array}$ \\
\hline Constant & & & & $\begin{array}{r}-0.050 \\
(-0.386) \\
\end{array}$ & $\begin{array}{l}-0.050 \text { *** } \\
(-3.625)\end{array}$ & $\begin{array}{l}-0.050^{* * * *} \\
(-3.625)\end{array}$ \\
\hline $\begin{array}{l}\text { \# obs. } \\
\text { \# clusters }\end{array}$ & 64 & 64 & 64 & $\begin{array}{r}265,984 \\
4,156\end{array}$ & $\begin{array}{r}265,984 \\
4,156\end{array}$ & 4,156 \\
\hline$R^{2}$ & 0.837 & 0.837 & 0.837 & 0.468 & 0.468 & 0.004 \\
\hline
\end{tabular}


Table IV

\section{A regression-based replication of the traditional calendar time portfolio approach for unbalanced panels}

This table reports the coefficient estimates and t-values (in parentheses) for two techniques of how to evaluate the performance of private investors. All results are based on an unbalanced panel of 11,340 private investors with end-of-month stock holdings at a renowned European wholesale bank from March 2000 to June 2005. Columns labeled with "CalTime" present the results for the traditional calendar time portfolio methodology. The dependent variable in the time-series regression of the first "CalTime" column is the net excess return of a zero-investment portfolio which is long (short) in the aggregated stock portfolio of all female (male) investors. In the second column which is labeled with "CalTime", the dependent variable is the net excess return of the aggregated portfolio of all male investors' stock-holdings. The dependent variable in the pooled OLS ("POLS") and pooled WLS ("PWLS") regression models is the monthly net excess return of the individual investors. In contrast to the pooled OLS regression where all observations are equally weighted, observation weights for the pooled WLS regressions are set equal to the reciprocal value of the number of women (men) with stock holdings in month $t$. The explanatory variables in the regressions are the monthly excess return of the Swiss Performance Index (SPI), the monthly excess return of the MSCI World index (World) orthogonalized by SPI, the return of a zero-investment book-tomarket portfolio $(H M L)$, the return of a zero-investment size portfolio $(S M B)$, a dummy variable being one if an investor is female (Woman), and all interactions between the Woman dummy and the aforementioned factor variables. The t-values of the various models are based on the following covariance matrix estimation techniques ( $S E$ type): NW87a refers to Newey and West (1987) standard errors (without degree-of-freedom correction), DK98 stands for Driscoll and Kraay (1998) standard errors, and $A 87$ denotes clustered or panel robust standard errors. $* * * * *$, and $*$ indicate significance at the 1,5 , and 10 percent levels.

\begin{tabular}{|c|c|c|c|c|c|}
\hline $\begin{array}{l}\text { Method } \\
\text { SE type }\end{array}$ & $\begin{array}{l}\text { CalTime } \\
\text { NW87a }\end{array}$ & $\begin{array}{l}\text { CalTime } \\
\text { NW87a }\end{array}$ & $\begin{array}{l}\text { PWLS } \\
\text { DK98 }\end{array}$ & $\begin{array}{l}\text { POLS } \\
\text { DK98 }\end{array}$ & $\begin{array}{l}\text { PWLS } \\
\text { A87 }\end{array}$ \\
\hline SPI*Woman & $\begin{array}{l}-0.0344 * * * \\
(-3.1144)\end{array}$ & & $\begin{array}{l}-0.0344 * * * \\
(-3.1144)\end{array}$ & $\begin{array}{l}-0.0343 * * * \\
(-3.1184)\end{array}$ & $\begin{array}{l}-0.0344 * * * \\
(-4.0055)\end{array}$ \\
\hline World*Woman & $\begin{array}{l}-0.1482 * * * \\
(-10.7340)\end{array}$ & & $\begin{array}{l}-0.1482 * * * \\
(-10.7340)\end{array}$ & $\begin{array}{l}-0.1491^{* * * *} \\
(-10.9954)\end{array}$ & $\begin{array}{l}-0.1482 \text { *** } \\
(-9.9839)\end{array}$ \\
\hline HML*Woman & $\begin{array}{l}-0.0197 * * \\
(-2.2248)\end{array}$ & & $\begin{array}{l}-0.0197 * * \\
(-2.2248)\end{array}$ & $\begin{array}{l}-0.0192 * * \\
(-2.2340)\end{array}$ & $\begin{array}{l}-0.0197 * * \\
(-2.1603)\end{array}$ \\
\hline SMB*Woman & $\begin{array}{l}-0.0645 * * * \\
(-4.0060)\end{array}$ & & $\begin{array}{l}-0.0645^{* * *} \\
(-4.0060)\end{array}$ & $\begin{array}{l}-0.0651^{* * * *} \\
(-3.9909)\end{array}$ & $\begin{array}{l}-0.0645 * * * \\
(-5.3169)\end{array}$ \\
\hline SPI & & $\begin{array}{l}1.1046^{* * * *} \\
(34.2870)\end{array}$ & $\begin{array}{l}1.1046^{* * * *} \\
(34.2870)\end{array}$ & $\begin{array}{l}1.1062 * * * * \\
(34.6479)\end{array}$ & $\begin{array}{l}1.1046 * * * \\
(209.5631)\end{array}$ \\
\hline World & & $\begin{array}{l}0.4957 * * * * \\
(11.0740)\end{array}$ & $\begin{array}{l}0.4957^{* * *} \\
(11.0740)\end{array}$ & $\begin{array}{l}0.4953^{* * * *} \\
(10.9755)\end{array}$ & $\begin{array}{l}0.4957 * * * \\
(51.1123)\end{array}$ \\
\hline HML & & $\begin{array}{l}0.2311^{* * *} \\
(6.3507)\end{array}$ & $\begin{array}{l}0.2311 * * * \\
(6.3507)\end{array}$ & $\begin{array}{l}0.2328 * * * \\
(6.4337)\end{array}$ & $\begin{array}{l}0.2311^{* * * *} \\
(42.6989)\end{array}$ \\
\hline SMB & & $\begin{array}{r}0.0261 \\
(0.7697)\end{array}$ & $\begin{array}{r}0.0261 \\
(0.7697)\end{array}$ & $\begin{array}{r}0.0256 \\
(0.7537)\end{array}$ & $\begin{array}{l}0.0261 \text { *** } \\
(3.4773)\end{array}$ \\
\hline Woman & $\begin{array}{l}0.0946 * * \\
(2.0644)\end{array}$ & & $\begin{array}{l}0.0946 * * \\
(2.0644)\end{array}$ & $\begin{array}{c}0.0878^{*} \\
(1.9379)\end{array}$ & $\begin{array}{l}0.0946^{* * * *} \\
(3.9098)\end{array}$ \\
\hline Constant & & $\begin{array}{r}-0.0892 \\
(-0.5599)\end{array}$ & $\begin{array}{r}-0.0892 \\
(-0.5599)\end{array}$ & $\begin{array}{r}-0.0707 \\
(-0.4590)\end{array}$ & $\begin{array}{l}-0.0892 * * * \\
(-5.7045)\end{array}$ \\
\hline $\begin{array}{l}\text { \# obs. } \\
\text { \# clusters }\end{array}$ & 64 & 64 & $\begin{array}{r}539,879 \\
11,340\end{array}$ & $\begin{array}{r}539,879 \\
11,340\end{array}$ & $\begin{array}{r}539,879 \\
11,340\end{array}$ \\
\hline$R^{2}$ & 0.777 & 0.972 & 0.350 & 0.354 & 0.350 \\
\hline
\end{tabular}


Table V

\section{What determines the performance of private investors?}

This table reports the coefficient estimates and t-values (in parentheses) from pooled OLS regressions with Driscoll-Kraay standard errors. The standard error estimates are heteroscedasticity consistent and robust to both cross-sectional dependence and autocorrelation up to three lags, respectively. The sample consists of 11,340 private investors with end-of-month stock holdings at a renowned European wholesale bank from March 2000 through June 2005 . In the regressions, the investors' monthly gross excess return $\left(y_{h, t}^{g r}\right)$ or their net excess return $\left(y_{h, t}^{n e t}\right)$ is the dependent variable and the explanatory variables are obtained by aid of a Kronecker expansion between the factors of a Fama and French (1993) like performance measurement model and a set of investor characteristics (see Section 2.3 for details). The factors of the performance measurement model are the excess return of the Swiss Performance Index (SPI), the excess return of the MSCI World index orthogonalized by the SPI, the return of a zero-investment book-to-market portfolio (HML), and the return of a zero-investment size portfolio (SMB). The investor characteristics considered are the monthly stock turnover (Stock turnover p.m.), a dummy variable being one for women (Woman), a dummy variable being one for investors who trade stocks over an online banking account (Online investor), the beginning-of-month $t$ number of stocks in the investors' portfolio (\# stock holdings), and the natural logarithm of the beginning-of-month $t$ stock portfolio value in $\mathrm{CHF}(\ln ($ stock wealth)). For brevity, the table only presents the results for the investor characteristics (which are contained in vector $\mathbf{z}_{h t}$ of regression (21)).***,**, and * indicate significance at the 1,5 , and 10 percent levels.

\begin{tabular}{|c|c|c|c|c|c|c|c|c|c|c|c|c|}
\hline $\begin{array}{l}\text { Hypothesis } \\
\text { Dependent variable }\end{array}$ & $\begin{array}{l}\mathrm{H} 1 \mathrm{a} \\
y_{h, t}^{g r}\end{array}$ & $\begin{array}{l}\mathrm{H} 1 \mathrm{~b} \\
y_{h, t}^{n e t}\end{array}$ & $\begin{array}{l}\mathrm{H} 2 \mathrm{a} \\
y_{h, t}^{n e t}\end{array}$ & $\begin{array}{l}\mathrm{H} 2 \mathrm{~b} \\
y_{h, t}^{n e t}\end{array}$ & $\begin{array}{c}\mathrm{H} 3 \\
y_{h, t}^{g r}\end{array}$ & $\begin{array}{c}\mathrm{H} 3 \\
y_{h, t}^{n e t}\end{array}$ & $\begin{array}{l}\mathrm{H} 4 \mathrm{a} \\
y_{h, t}^{g r}\end{array}$ & $\begin{array}{l}\mathrm{H} 4 \mathrm{a} \\
y_{h, t}^{n e t}\end{array}$ & $\begin{array}{l}\mathrm{H} 4 \mathrm{~b} \\
y_{h, t}^{g r}\end{array}$ & $\begin{array}{l}\mathrm{H} 4 \mathrm{~b} \\
y_{h, t}^{n e t}\end{array}$ & $\begin{array}{c}\text { All } \\
y_{h, t}^{g r}\end{array}$ & $\begin{array}{c}\text { All } \\
y_{h, t}^{n e t}\end{array}$ \\
\hline Stock turnover p.m. & $\begin{array}{r}-0.373 \\
(-0.198)\end{array}$ & $\begin{array}{l}-3.693^{* *} \\
(-2.039)\end{array}$ & & $\begin{array}{l}-3.608 * * \\
(-1.998)\end{array}$ & & & & & & & $\begin{array}{r}0.153 \\
(0.081)\end{array}$ & $\begin{array}{c}-3.164^{*} \\
(-1.758)\end{array}$ \\
\hline Woman & & & $\begin{array}{l}0.088^{*} \\
-1.938\end{array}$ & $\begin{array}{r}0.066 \\
(1.528)\end{array}$ & & & & & & & $\begin{array}{r}0.034 \\
(0.804)\end{array}$ & $\begin{array}{r}0.039 \\
(0.923)\end{array}$ \\
\hline Online investor & & & & & $\begin{array}{l}-0.194 * * * \\
(-2.649)\end{array}$ & $\begin{array}{l}-0.271 * * * \\
(-3.661)\end{array}$ & & & & & $\begin{array}{l}-0.164 * * * \\
(-3.170)\end{array}$ & $\begin{array}{l}-0.163^{* * *} \\
(-3.035)\end{array}$ \\
\hline \# stock holdings & & & & & & & $\begin{array}{l}-0.019^{* *} \\
(-2.131)\end{array}$ & $\begin{array}{l}-0.020^{* *} \\
(-2.303)\end{array}$ & $\begin{array}{r}-0.015 \\
(-1.168)\end{array}$ & $\begin{array}{r}-0.018 \\
(-1.363)\end{array}$ & $\begin{array}{c}-0.017^{*} \\
(-1.760)\end{array}$ & $\begin{array}{c}-0.017^{*} \\
(-1.751)\end{array}$ \\
\hline $\ln$ (stock wealth) & & & & & & & & & $\begin{array}{r}-0.015 \\
(-0.180)\end{array}$ & $\begin{array}{r}-0.009 \\
(-0.111)\end{array}$ & & \\
\hline Constant & $\begin{array}{r}0.038 \\
(0.317)\end{array}$ & $\begin{array}{r}0.031 \\
(0.256)\end{array}$ & $\begin{array}{r}-0.071 \\
(-0.459)\end{array}$ & $\begin{array}{r}0.006 \\
(0.047)\end{array}$ & $\begin{array}{r}0.058 \\
(0.436)\end{array}$ & $\begin{array}{r}-0.000 \\
(-0.001)\end{array}$ & $\begin{array}{r}0.107 \\
(0.654)\end{array}$ & $\begin{array}{r}0.044 \\
(0.267)\end{array}$ & $\begin{array}{r}0.197 \\
(0.215)\end{array}$ & $\begin{array}{r}0.077 \\
(0.084)\end{array}$ & $\begin{array}{r}0.109 \\
(0.703)\end{array}$ & $\begin{array}{r}0.099 \\
(0.636)\end{array}$ \\
\hline \# obs. & 539,879 & 539,879 & 539,879 & 539,879 & 539,879 & 539,879 & 539,879 & 539,879 & 539,879 & 539,879 & 539,879 & 539,879 \\
\hline \# clusters & 11,340 & 11,340 & 11,340 & 11,340 & 11,340 & 11,340 & 11,340 & 11,340 & 11,340 & 11,340 & 11,340 & 11,340 \\
\hline$R^{2}$ & 0.356 & 0.356 & 0.354 & 0.357 & 0.355 & 0.355 & 0.354 & 0.354 & 0.363 & 0.363 & 0.359 & 0.359 \\
\hline
\end{tabular}




\section{Do CHF denominated stockholdings of Swiss residents outperform those of non-Swiss residents?}

This table reports the coefficient estimates and t-values (in parentheses) from pooled OLS regressions on the investor level. The sample consists of 11,340 private investors with end-of-month stock holdings at a renowned European wholesale bank from March 2000 through June 2005. The regression specification is as follows:

$$
y_{h, t}^{g r}=\left(\mathbf{z}_{h t} \otimes \mathbf{x}_{t}\right) \mathbf{d}+v_{h t}
$$

where the dependent variable $\left(y_{h, t}^{g r}\right)$ is the investors' monthly gross excess return, vector $\mathbf{x}_{t}$ contains the factors of a Fama and French (1993) like performance measurement model, vector $\mathbf{z}_{h t}$ includes a set of investor characteristics, and vector $\mathbf{d}$ includes the regression coefficients. The factors of the performance measurement model are the excess return of the Swiss Performance Index (SPI), the excess return of the MSCI World index orthogonalized by the SPI, the return of a zero-investment book-to-market portfolio (HML), and the return of a zero-investment size portfolio (SMB). The investor characteristics considered are a dummy variable which is 1 for Swiss residents (Swiss), the investors' beginning-of-month $t$ portfolio weight of Swiss stocks (WCHF), an interaction term between the Swiss dummy and variable WCHF (Swiss*WCHF), the monthly stock turnover (Stock turnover p.m.), a dummy variable being one for women (Woman), a dummy variable being one for investors who trade stocks over an online banking account (Online investor), and the beginning-of-month $t$ number of stocks in the investors' portfolio (\# stock holdings). The t-values of the regressions rely on the following covariance matrix estimators (SE type): $O L S$ are OLS standard errors, A87 refers to clustered or panel robust standard errors, and DK98 stands for Driscoll and Kraay (1998) standard errors. For brevity, the table only presents the results for the investor characteristics (which are contained in vector $\mathbf{z}_{h t}$ ). ${ }^{* * *}$ and ${ }^{* *}$ indicate significance at the 1 and 5 percent levels.

\begin{tabular}{|c|c|c|c|c|c|c|}
\hline \multirow{2}{*}{$\begin{array}{l}\text { Test of } \\
\text { SE type }\end{array}$} & \multicolumn{3}{|c|}{ Hypothesis 5} & \multicolumn{3}{|c|}{ Hypotheses 1 through 5} \\
\hline & OLS & A87 & DK98 & OLS & A87 & DK98 \\
\hline Swiss & $\begin{array}{l}-0.1733 \text { *** } \\
(-3.2634)\end{array}$ & $\begin{array}{l}-0.1733 * * \\
(-2.2253)\end{array}$ & $\begin{array}{r}-0.1733 \\
(-1.0947)\end{array}$ & $\begin{array}{l}-0.1290 * * \\
(-2.4183)\end{array}$ & $\begin{array}{r}-0.1290 \\
(-1.6447)\end{array}$ & $\begin{array}{r}-0.1290 \\
(-0.8343)\end{array}$ \\
\hline WCHF & $\begin{array}{l}0.3027 * * * \\
(4.9155)\end{array}$ & $\begin{array}{l}0.3027 \text { *** } \\
(5.1647)\end{array}$ & $\begin{array}{r}0.3027 \\
(1.0597)\end{array}$ & $\begin{array}{l}0.2977 * * * \\
(4.8344)\end{array}$ & $\begin{array}{l}0.2977 \text { *** } \\
(5.0743)\end{array}$ & $\begin{array}{r}0.2977 \\
(1.0396)\end{array}$ \\
\hline Swiss*WCHF & $\begin{array}{l}0.2247 * * * \\
(3.0569)\end{array}$ & $\begin{array}{l}0.2247 * * \\
(2.4546)\end{array}$ & $\begin{array}{r}0.2247 \\
(1.1134)\end{array}$ & $\begin{array}{l}0.1853^{* *} \\
(2.5253)\end{array}$ & $\begin{array}{l}0.1853^{* *} \\
(2.0196)\end{array}$ & $\begin{array}{r}0.1853 \\
(0.9322)\end{array}$ \\
\hline Stock turnover p.m. & & & & $\begin{array}{r}0.4413 \\
(1.3122)\end{array}$ & $\begin{array}{r}0.4413 \\
(0.6020)\end{array}$ & $\begin{array}{r}0.4413 \\
(0.2327)\end{array}$ \\
\hline Woman & & & & $\begin{array}{r}0.0096 \\
(0.3954)\end{array}$ & $\begin{array}{r}0.0096 \\
(0.4115)\end{array}$ & $\begin{array}{r}0.0096 \\
(0.2798)\end{array}$ \\
\hline Online investor & & & & $\begin{array}{l}-0.1394 * * * \\
(-4.1393)\end{array}$ & $\begin{array}{l}-0.1394 * * * \\
(-3.4633)\end{array}$ & $\begin{array}{l}-0.1394 * * * \\
(-3.2500)\end{array}$ \\
\hline \# stock holdings & & & & $\begin{array}{l}-0.0121 * * * \\
(-4.9872)\end{array}$ & $\begin{array}{l}-0.0121 \text { *** } \\
(-5.4726)\end{array}$ & $\begin{array}{r}-0.0121 \\
(-1.3002)\end{array}$ \\
\hline Constant & $\begin{array}{l}-0.1959 \text { *** } \\
(-4.8810)\end{array}$ & $\begin{array}{l}-0.1959 \text { *** } \\
(-4.4420)\end{array}$ & $\begin{array}{r}-0.1959 \\
(-0.7273)\end{array}$ & $\begin{array}{l}-0.1430 \text { *** } \\
(-3.2842)\end{array}$ & $\begin{array}{l}-0.1430 * * * \\
(-2.8690)\end{array}$ & $\begin{array}{r}-0.1430 \\
(-0.5073)\end{array}$ \\
\hline \# obs. & 539,879 & 539,879 & 539,879 & 539,879 & 539,879 & 539,879 \\
\hline \# clusters & 11,340 & 11,340 & 11,340 & 11,340 & 11,340 & 11,340 \\
\hline$R^{2}$ & 0.376 & 0.376 & 0.376 & 0.380 & 0.380 & 0.380 \\
\hline
\end{tabular}




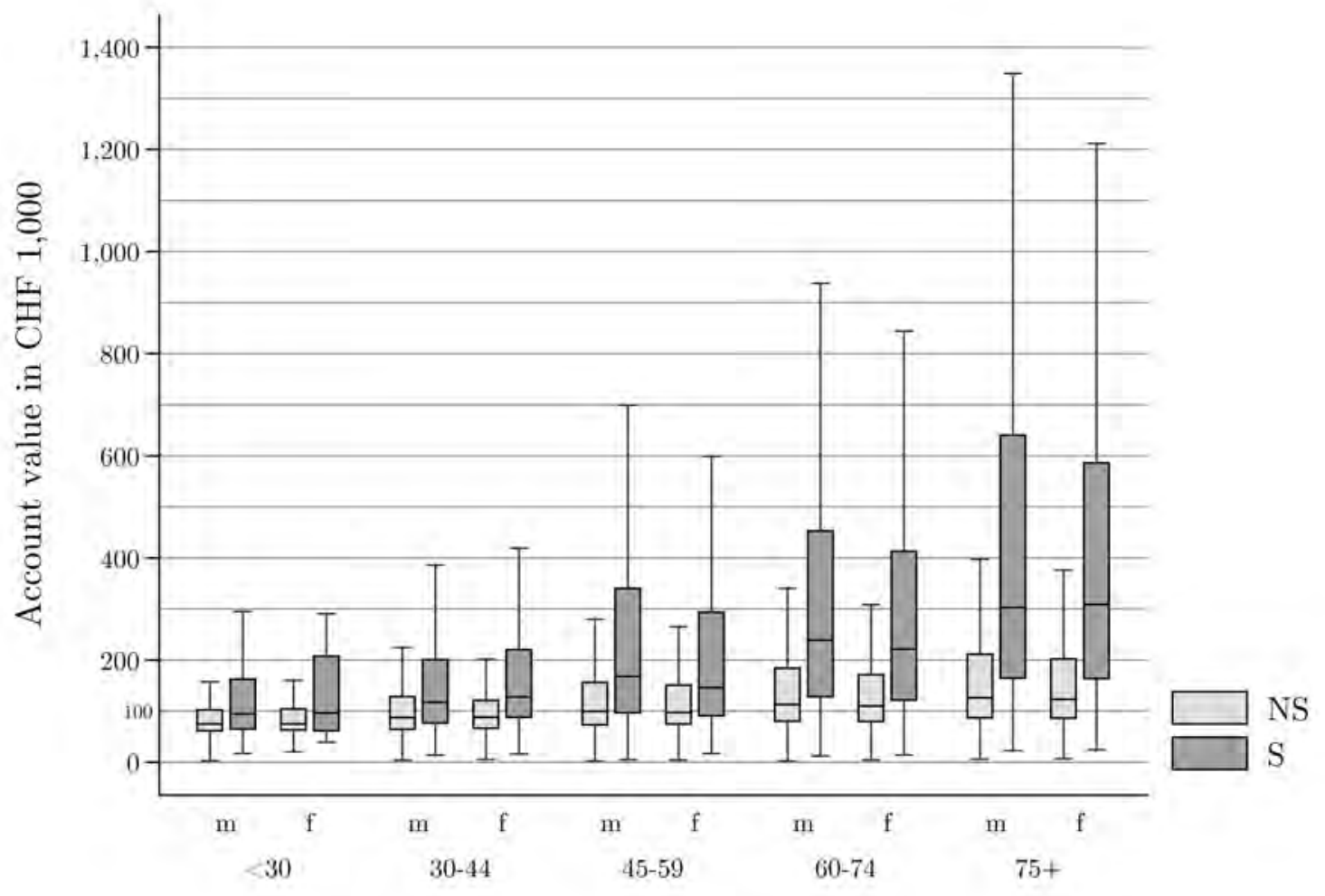

Figure 1. The relationship between age, sex, and financial wealth.

The figure displays box plots of the investors' average account value in CHF 1,000 grouped by age (in year 2005), sex, and whether or not they hold common stocks. The sample period is from March 2000 through June 2005. " $\mathrm{m}$ " and "f" denote male and female investors, respectively. Investors with (without) position holdings in common stocks are labeled by "S" ("NS"). The middle line in the box plots depicts the median account value of the investor groups and the lower (upper) border line of the boxes show the lower (upper) quartiles of the investor groups' bank wealth. 